\title{
PREHISTORIC SETTLEMENT, MOBILITY AND SOCIETAL STRUCTURE IN THE PEAK DISTRICT NATIONAL PARK: NEW EVIDENCE FROM CERAMIC COMPOSITIONAL ANALYSIS
}

\author{
K. V. E. COOTES ${ }^{1}$ and P. S. QUINN ${ }^{2}$ \\ ${ }^{1}$ Department of Archaeology, University of Sheffield, Northgate House, Sheffield, S1 4ET.
}

${ }^{2}$ Institute of Archaeology, University College London, 31-34 Gordon Square, London, WC1H OPY.

Detailed compositional and technological analysis of a large assemblage of prehistoric ceramics from numerous sites situated within the Peak District National Park has been used to explore the settlement patterns, societal structure, mobility and interaction of the populations that inhabited this area during the Early Bronze Age to Early Iron Age. A surprising pattern emerges of the widespread dominance of a single, geographically restricted temper type, which appears to have been transported and mixed with locally procured clay and used to produce pottery at numerous different sites. The distribution of this and several other compositional groups are defined via thin section petrography and compared to raw material field samples. The resulting patterns are used to assess the validity of previous theories about prehistoric life in this region during the third to first millennia $B C$.

KEYWORDS: PREHISTORIC CERAMICS, SETTLEMENT PATTERNS, MOBILITY, RESOURCE EXPLOITATION, THIN SECTION PETROGRAPHY 


\section{LAND USE, SETTLEMENT AND SOCIETAL STRUCTURE IN THE}

\section{PREHISTORIC PEAK DISTRICT}

The topographically isolated, largely undeveloped uplands of the Peak District National Park in Derbyshire and Staffordshire (Fig 1(a)) contain some of the most extensive remains of Bronze Age habitation in Britain. This makes them an ideal region to investigate the organisation and development of prehistoric society during this important period, which is thought to be characterised by fundamental shifts in burial customs, settlement patterns (Barrett 1980; Champion 2002) and the nature of lithic, pottery and metalwork assemblages (Parker Pearson 2002, 2005, 77). Research into the archaeological and environmental record of the Peak District has resulted in several competing theories on landscape use, mobility and social relations (e.g. Hawke-Smith 1979, 1981; Barnatt 1999, 2000; Kitchen 2000).

The Peak District is characterised by two main landscape zones, the White Peak and Dark Peak (Fig 1(b)), defined by their underlying geology, topography, resources and land use in the past, and at the present day. The central limestone plateau of the White Peak, with its lower altitude and more fertile soils, was initially postulated to represent the core of prehistoric habitation by mobile populations (Fowler 1955; Armstrong 1956), with the lower status, peripheral, rugged landscape of the Dark Peak being occupied during times of population pressure (Hawke-Smith 1979, 1981; Hicks 1971). However, the discovery of extensive prehistoric field systems on the Eastern Gritstone Moors of the Dark Peak, west of Sheffield (Fig 1(b)), suggested that this area could have been inhabited by small sedentary farming communities who 'settled down' during the Late Neolithic to Early Bronze Age (Barnatt 1999, 2000). This called for a reconsideration of the traditional core-periphery model of Hawke-Smith $(1979,1981)$ 
and suggested a more widespread pattern of self-sufficient families. Reassessment of the prehistoric archaeological remains of the Peak District and adjacent areas then led to the development of a further model, defined by wide-scale mobility and multiple land-use strategies (Kitchen 2000), with large social groups regularly moving into and out of the region during the Late Neolithic and most of the Bronze Age. The subsequent rise of several defended hillforts in the area covered by the Peak District during the Late Bronze Age to Early Iron Age seems to indicate greater social differentiation in later prehistory and a more territorial subdivision of the landscape (Barnatt 1999).

The prevalent models of Peak District land-use, settlement patterns and societal structure have been based mainly on the nature and distribution of standing monuments, prehistoric field systems and evidence of habitation. Burials, lithic scatters, pollen and ceramics have also played an important role. The latter occur in significant numbers at most prehistoric sites in the region, including cairns, barrows, stone circles, hillforts and domestic contexts, and are well preserved in the acidic soils of the Dark Peak, where bone rarely survives. Stylistic connections between the ceramics of specific sites (e.g. Barrett 1979; Barnatt and Smith 2004, 23) hold potential for interpreting the territories of different social groups and their interaction with one another. Furthermore, initial scientific analyses on the composition of small numbers of pottery sherds by Guilbert and Vince (1996) have highlighted the information they contain about the mobility of prehistoric populations and their utilisation of the geologically diverse landscape of the Peak District.

The present study makes fuller use of the interpretative potential of the prehistoric ceramic record of the Peak District in order to assess the validity of the various models of settlement, societal structure and cultural development proposed for this archaeologically important upland area. A total of 233 sherds have been studied from 24 
Early Bronze Age to Early Iron Age sites across the White and Dark Peak. The primary objectives were the detection of patterns of landscape use, mobility and interaction both between and within the two main landscape zones, and the observation of changes in the ceramic record over time that may be indicative of larger societal shifts. Pottery has been analysed via a detailed petrographic approach, defining compositional groups seen in thin section under the microscope, that reflect the use of specific raw materials and paste preparation technology. Analytical results are then linked to the prehistoric landscape via their geological characteristics, mapping the distribution of fabric units across space and time.

\section{STUDY MATERIALS AND SCIENTIFIC METHODOLOGY}

The 24 analysed sites cover a broad area of the present day Peak District National Park, including both the White and Dark Peak landscape zones (Fig 1(b)) (Table 1). They comprise recent research excavations such as Gardom's Edge on the Eastern Gritstone Moors (Barnatt et al. 2002) as well as $19^{\text {th }}$ century antiquarian investigations (e.g. Bateman 1861; Bateman and Glover 1848). Despite the lack of secure dates for the latter, all of the sampled ceramics can be broadly classified to either the Early-Middle Bronze Age (EBA-MBA) or the Late Bronze Age-Early Iron Age (LBA-EIA).

The EBA-MBA pottery $(n=47)$ comes from numerous funerary contexts, and in many cases, consists of a single sherd recovered from a barrow (e.g. Bailey Hill, Dove Dale, Sheldon) (Table 1). Larger numbers of samples were taken from the cemeteries of Eaglestone Flat and Stanton Moor. In comparison, the LBA-EIA material (n $=186$ ) originates from a smaller number of settlement sites, but comprise the majority of sampled sherds. This difference reflects the nature of the prehistoric remains in the 
Peak District, as well as its excavation. At the settlement of Gardom's Edge (Ainsworth and Barnatt 1998) and the hillfort of Mam Tor (Coombs and Thompson 1979) it was possible to sample ceramics from several separate dwellings.

Due to the destructive nature of the scientific analysis, rims, profiles, bases and sherds with decoration had to be avoided in most cases. Nevertheless, a wide range of vessel forms were sampled including Beakers, Cordoned Urns, Collared Urns, one Food Vessel and a single Accessory Vessel. All samples were studied typologically before being prepared as standard $30 \mu \mathrm{m}$ thin sections. The thin sections were analysed under the polarising light microscope at magnifications of x25-400 using a descriptive, semi-quantitative approach (Quinn 2013, 71-102). The 233 samples were grouped into petrographic 'fabrics' based on the composition, abundance, shape, size and distribution of their dominant mineral and rock inclusions, as well as the nature of the clay matrix and voids. This was performed without reference to the archaeological details of the sherds, in order to identify fabrics that occur at different sites, as well as within several periods and across multiple pottery styles.

A campaign of raw material prospecting and analysis was undertaken in the immediate vicinity of each site in order to assess the availability of clay-rich deposits that may have been suitable for pottery production. A total of 24 clay samples from nine sites were processed in the laboratory, fired, thin sectioned and compared directly to the detected ceramic fabrics (Fig 2). Specific hard rock samples were also collected for comparison with the lithic inclusions within the sherds.

The presence of basic igneous inclusions in many samples, necessitated the extensive sampling of rock outcrops of this material. Isolated basaltic lava flows, tuffs and thin dolerite sills occur in several parts of the Carboniferous limestone plateau of the White Peak (Aitkenhead and Waters 2002) (Fig 2), but are absent in the thick mass 
of non-marine sandstone and shale that underlies the uplands of the Dark Peak. A total of 55 basic igneous samples from 24 outcrops were thin sectioned in order to characterise these outcrops and identify the source(s) of the material in the ceramics (Fig 2). Attention was also given to the patchy superficial Quaternary deposits that occur within the Peak District, including glacial till and head.

In addition to the 233 pottery sherds, 21 fragments of possible clay daub recovered from the sites of Fin Cop on the White Peak and Gardom's Edge on the Dark Peak were also analysed. Clay used for architectural purposes is often thought to have been locally procured, so it was reasonable to postulate that these artefacts would append the raw material samples collected from at the two sites.

\section{COMPOSITION AND DISTRIBUTION OF CERAMIC FABRICS}

The 233 analysed prehistoric sherds can be classified in thin section into 18 separate petrographic fabrics and several sub-fabrics (Fig 3; Appendices 1 and 2). Despite this compositional diversity, $84 \%$ of the samples are characterised by the presence of inclusions of fine or medium grained basic igneous rock (Fabrics 1-3; Fig 3) (Table 1). This distinctive material, which can be identified geologically as either basalt or dolerite, occurs mainly as sand-sized grains (0.6-2 mm), which appear to have been intentionally added as temper from the crushing of weathered rock, due to their sub-angular to subrounded shape and the bimodal grain size of the inclusions in the samples (Fig 3 (b)). Ceramics containing basic igneous temper occur at half of the 24 sampled sites on the White and Dark Peak, including barrows, cemeteries, settlements and hillforts. The sherds come from a variety of different ceramic forms such as Beakers, Collared and Cordoned Urns, Flat Rimmed cooking vessels, globular pots and a single Food Vessel. 
Basic igneous dominated fabrics are more common among the LBA-EIA ceramics (90\%) than the EBA-MBA material (59\%).

In most cases, basic igneous rock is the dominant inclusion type (Fabric 1). However, it also occurs alongside quartz sand in LBA-EIA ceramics from the hillfort of Fin Cop on the White Peak (Fabric 2; Fig 3 (e)). Crushed pottery sherds ('grog') and basic igneous rock were added as filler to the ceramics of Fabric 3 (Fig 3(f)). These latter sherds have a widespread geographic and chronological distribution in our dataset. Significant variation appears to occur within the 'base clay' to which temper was added in Fabrics 1 and 3.

Sherds characterised by petrographic fabrics in which basic igneous material is absent are numerically less abundant and have a more restricted distribution in the analysed material. These include grog-tempered Beakers and Collared Urns from EBAMBA burial sites on both the White and Dark Peak (Fabric 5) as well as various Urns with chert inclusions recovered from the Dark Peak and Beakers from the White Peak (Fabrics 11). Sandstone tempered (Fabrics 6 and 10) and acid igneous tempered (Fabrics 7,9$)$ LBA-EIA ceramics were recovered from several sites in the Dark Peak. Single oddities in the dataset include an EBA-MBA sherd containing crushed bone fragments (Fabric 13).

Little correspondence exists between the vessel type and function interpreted for the analysed sherds and their petrographic composition. Classes such as Beakers, Collared Urns and Cordoned Urns, which are restricted to the EBA-MBA in our dataset, vary in paste recipe on a site specific basis.

CERAMIC RAW MATERIAL SOURCES 
The overwhelming dominance of a common petrographic composition within the chronologically and geographically expansive ceramic dataset analysed in this study is a surprising discovery. While outcrops of basic igneous rock occur in several parts of the White Peak (Figs 2, 4, Appendix 3), these are small and therefore localised within the dominantly limestone bedrock. Furthermore, primary exposures are entirely absent in the Dark Peak.

Basic igneous rock can be characterised and classified based upon the proportions of mineral crystals present, as well as their size and arrangement (Fig 4, Appendix 3). The individual inclusions of this type in the analysed ceramics are composed of plagioclase feldspar, with augite and/or olivine crystals and can be classified as either fine-grained 'basalt' (Figs 3(a) and (b)) or medium-grained 'dolerite' (Figs 3(e) and (f) based on their texture. Significant diversity is present both between and within the sherds in terms of crystal size, the proportion of olivine, the presence/absence of air bubbles or 'vesicles' and the degree of weathering. Analysis of 55 field samples of basic igneous rock from the White Peak has permitted this variation to be contextualised, and points to several possible sources that could have been utilised as temper for the ceramics. Multiple samples taken from single outcrops as well as several exposures of the same igneous body, reveal that they are largely homogeneous in terms of their composition and in many cases exhibit small but significant differences between one another.

Ceramics from eight of the archaeological sites contained basic igneous inclusions that could be matched with specific occurrences of this material, such as the Late Bronze Age hillfort of Fin Cop. All sherds analysed from this site contain inclusions of olivine-rich vesicular basalt with 'amygdaloidal' infilling and high iron content, which corresponds well to the prominent volcanic outcrop of Black Rock Corner in the Wye 
Valley, a little over $1 \mathrm{~km}$ away (Fig 2). The columnar basalt lava flow of Cave Dale near Castleton (Fig 2) was found to be petrographically similar to weathered chloriterich inclusions that occur in ceramics from several sites. Examples occur at the nearby hillfort of Mam Tor, and the more distant settlement of Gardom's Edge and barrow cemetery of Stanton Moor. In addition, basalt and dolerite samples collected from disused quarries near Tideswell (Fig 2) matched certain sherds from the hilltop enclosure of Ball Cross c. $8 \mathrm{~km}$ to the south, in that they were rich in olivine and weathered to a brown colour.

The above matches may be indicative of the specific origin(s) of basic igneous temper within the prehistoric ceramics of Fabrics 1-3. These occur at several sites and will be explored in more detail below. In other cases, it is not possible to distinguish between two or more possible sources for the basic igneous material in the analysed ceramics due to a lack of distinctive mineralogical, textural or preservational characteristics and the compositional similarity between some of the sampled outcrops. No matches were recorded for the dolerite outcrops of the Peak Forest area (Fig 2), which are characterised by particularly coarse mineral crystals.

The possible temper sources identified through petrographic analysis are in some instances close to the find spot at which the ceramics were excavated, for example the LBA-EIA hillforts of Fin Cop and Mam Tor. At other sites, such as the EBA-MBA ringwork of Totley Moor, they may be located up to $22 \mathrm{~km}$ away. In the case of many of the sites located on the Dark Peak that yielded basic igneous ceramics, it is not possible that the temper could have been locally procured due to the lack of primary outcrops of this material. While prehistoric potters are known to have selected igneous clasts from superficial glacial deposits in several parts of Britain (e.g. Freestone and Middleton 1991; Wardle 1991), sediment of this type has a very patchy distribution 
within the Peak District, which may have remained largely free of ice during the last glacial period (Brandon 2002).

The sources of temper used in the less common, non-basic igneous petrographic fabrics are more difficult to pin-point. Sandstone, which may have been added to five LBA-EIA samples from Mam Tor in the Dark Peak (Fabric 6) and a single EBA-MBA sherd from the Barrow of Sheldon in the White Peak (Fabric 10), is abundant within the Namurian strata of the Dark Peak (Fig 2) and outcrops as numerous steep cliffs across this moorland area. As such, it would have been readily available to prehistoric potters, though more difficult to obtain at sites in the White Peak. Nodules and bands of chert occur sporadically within the Carboniferous limestone plateau, perhaps indicating a White Peak source for the ceramics of Fabrics 11, 12, 14-17, which contain this material. However, all but one of the sherds within these fabrics come from EBA-MBA sites within the Dark Peak, particularly Stanton Moor. Distinguishing between specific deposits of chert on petrographic evidence alone is unfortunately not possible. Fabrics 15 and 16, contain weathered inclusions of porphyritic acid igneous rock, as does Fabric 7. Primary exposures of volcanic acidic igneous rock such as rhyolte and rhyodacite do not occur in the Peak District, or the immediately adjacent areas.

\section{LOCATION OF POTTERY PRODUCTION}

The occurrence at several EBA-MBA and LBA-EIA sites of pottery containing temper from non-local sources can be interpreted in terms of either the transport of raw materials or the movement of finished pots. In provenance studies of archaeological ceramics, it is usually assumed that clay and temper were obtained close to the site of pottery production (Tite 1999, 195; Quinn 2013, 119). This is based on observations of the raw 
material procurement distances of traditional potters in sedentary communities (Arnold 1985, 32-60), as well as the effort required to transport bulky raw materials, and the often common occurrence of useable clay and temper sources in the landscape. However, exceptions to this rule exist, such as pottery making by certain mobile populations (e.g. Heizer and Treganza 1972, 334; May and Tuckson 2000, 23), who may have combined raw material procurement with other subsistence or social activities (Michelaki et al. 2014), enabling them to make use of specific favoured non-local deposits.

The occurrence within Fabrics 1-3 of basalt and dolerite inclusions from several different igneous outcrops appears to rule out the production of these ceramics at a single location and their subsequent distribution to various sites. While such a process has been proposed for other prehistoric ceramics, such as the gabbroic pottery of southwest Britain (Peacock 1988; Vince 1998; Harrad 2004), it seems unlikely that diverse basic igneous material was brought to a single location, used as temper and then redistributed within finished pots. Variation in the composition of the base clay to which basic igneous temper was added in Fabrics 1 and 3 may also rule out such a scenario and point instead to pottery production at several different locations. Possible matches between ceramics and sampled clay deposits at specific sites seem to support this. For example, clay containing quartz sand inclusions collected from the Wye Valley below the hillfort of Fin Cop resembled that used to manufacture LBA-EIA ceramics from this site (Fig 5(a) and (b)) and distinctive variegated material sampled at Gardom's Edge was a good match for the heterogeneous clay matrix of the basic igneous tempered ceramics from this site (Fig 5(c) and (d)).

An additional line of evidence to support the production of pottery at several different prehistoric sites using transported basic igneous material is the detailed analysis of the 'daub' recovered from Fin Cop and Gardom's Edge. All but two of these c. 
2-3 cm fragments turned out to be small pieces of weathered basalt or dolerite (Fig 6, Appendix 4) that matched the inclusions in certain sherds from the two sites. As primary outcrops of basic igneous material are not present in the Dark Peak and glacial material is scarce, they must have been intentionally brought to both sites. As such, they could represent the unused remains of temper material that was added to locally produced ceramics.

Basic igneous rock is known to have been sought out by prehistoric potters in several parts of Britain for use as temper material (Wardle 1992, 106; Williams and Jenkins 1999). It has a similar thermal expansion coefficient to fired ceramic when heated due to the presence of abundant feldspars (Rye 1976), making it an ideal filler for coarseware cooking vessels (Sheridan 1997, 329). However, other types of temper such as grog and calcite have comparable mechanical properties and would have perhaps been more readily available at many of the study sites. Furthermore, a technological explanation for the use of basic igneous rock does not account for its use as temper within Urns and Beakers, which seem to have served non-utilitarian functions. Instead, the selection of basalt and dolerite from localised exposures in the White Peak and its transport over significant distances may have been driven by other less functional reasons. Volcanic rock could have had specific tactile or aesthetic significance to the prehistoric inhabitants of the Peak District (Woodward 2008). It may also have been imbued with symbolic meaning that cannot be understood in terms of its physical or behavioural characteristics. Such an idea has been proposed by Williams and Jenkins (1999) for the production of Bronze Age urns from Anglesey, Wales, that are overwhelmingly tempered with basic igneous rocks of basalt and dolerite. Choice of temper can also have cultural value and be linked to specific pottery-making traditions and group identity (Quinn and Burton 2009). 
Among the other, rarer fabrics, there appears to be petrographic evidence for both the on-site production of pottery using locally available raw materials (e.g. Fabric 6, Mam Tor; Fabric 12, Hay Top), as well as the import of either temper raw materials or finished pots (e.g. Fabric 7, Mam Tor and Ball Cross; Fabric 11, Stanton Moor). The occurrence of ceramics containing acid igneous inclusions may be explained in terms of the recycling of imported material used for stone tool manufacture, particularly as this occurs in small amounts alongside basic igneous temper in Fabric 1A at Ball Cross and Gardom's Edge. Collared Urn and Beaker sherds tempered with grog, detected at six EBA-MBA barrows in the White Peak, are particularly difficult to provenance based on their dominant inclusions and thus their origin remains uncertain.

\section{IMPLICATIONS FOR LAND USE, SETTLEMENT AND SOCIETAL STRUCTURE}

The interpretations of pottery provenance and raw material sources presented above, as well as the geographic and chronological patterns of ceramic composition and manufacturing technology, have important implications for our view of prehistoric land use, settlement and societal structure in the Peak District. They provide new evidence with which to assess the validity of the various models proposed for this upland region.

The most surprising find is the dominance within the dataset of a single temper type. This is unexpected given the geological heterogeneity of the region and the relatively localised distribution of the basic igneous material that was used. Such a pattern appears to contradict the view of self-sufficient farming communities with their own identity, who had "everything necessary for their everyday practical and spiritual wellbeing", which was postulated by Barnatt and Smith $(2004,25)$. Their proposal was 
based on the well-preserved evidence of numerous prehistoric fields and associated monuments on the Eastern Gritstone Moors, which they envisaged being inhabited by individual sedentary family groups. However, the strong compositional and typological links between ceramics recovered from a wide area of the Peak District, including the Eastern Gritstone Moors, revealed by this study, does not support the local emphasis seen by these authors, and also put forward in Barnatt (1999). Instead, it appears that people living on the Dark Peak may have had a common identity that was also shared with inhabitants of the White Peak and manifested itself, amongst other things, in the technology of pottery production.

The use at sites on the Eastern Gritstone Moors and elsewhere in the Dark Peak of a specific temper type that was not locally available, also suggests that these communities clearly did not have all that they needed for their practical and spiritual wellbeing. Instead, they obtained certain essential resources, such as highly prized basic igneous rock, or perhaps pottery made from it, from more distant locations. This implies a greater level of mobility than is permitted by the model of Barnatt $(1999,2000)$, and/or significant interaction with other families or groups. He imagined the prehistoric inhabitants of the Peak District 'settling down' during the Late Neolithic-Early Bronze Age, earlier than elsewhere in Britain. However, this process is not supported by our data, which records a dominance $(71 \%)$ of basic igneous rock temper within EBAMBA ceramics at sites on the Dark Peak, as well as the use of other non-local resources such as chert, for the production of urns. An even greater proportion of non-local temper (92\%) was detected in the LBA-EIA, perhaps suggesting that far from having settled down within self-sufficient farming communities, the later prehistoric inhabitants of the area were moving and/or interacting more widely than before. 
The movement of raw materials and people indicated by our petrographic analysis of ceramics and geological field samples from the Peak District may provide support for the alternative model of Kitchen (2000), who proposed wide-scale mobility and multiple land-use strategies for both the Neolithic and Bronze Age. His interpretation relied heavily upon flints recovered from extensive field walking, as well as a reassessment of a range of other archaeological evidence. According to his view, specific monuments served as meeting points along established routes across the region, where ideas and material culture were exchanged. The widespread use of basic igneous temper could be seen to support this, with the prized raw material changing hands, or perhaps the knowledge of how to use it being shared. His proposition is certainly more in line with the homogeneity detected in the present dataset, than the isolated, self-sufficient communities and static settlement pattern seen on the Eastern Gritstone Moors by Barnatt $(1999,2000)$, which he also projected onto the rest of the Peak District (Kitchen 2000, 296-310).

Our extensive ceramic compositional database can also be used to shed light on the relative importance of the White and Dark Peak landscape zones in prehistoric times (Fowler 1955; Armstrong 1956; Hicks 1971). The limestone plateau was originally seen as the core of habitation due to its lower altitude and more fertile soil, compared to the peripheral, seemingly poorer landscape of the gritstone uplands, which was considered to be used less frequently (Hawke-Smith 1979, 1981). However, Barnatt's (1999, 2000) discovery of extensive field systems on the Eastern Gritstone Moors proved that the Dark Peak was also used by prehistoric people over several millennia, though perhaps on an intermittent basis (Kitchen 2000, 289-313). The compositional similarity between pottery assemblages from both landscape zones in this report, particularly during the LBA-EIA, could perhaps be seen to support this homogeneity in 
settlement across the region in the Bronze Age, as well as the similar status of the inhabitants in both areas (Barnatt and Collis 1996, 44-79; Barnatt 1999).

If the distribution of basic igneous rock, as well as other temper types such as chert are taken into account, then possible support for a White Peak core could perhaps be argued. Basalt and dolerite, which overwhelmingly dominate the inclusions of the 233 sherds analysed in the present study, are both restricted to the Carboniferous limestone plateau, indicating that this landscape was a key area for resource procurement and could have had a special significance to the inhabitants of the Peak District. This may also have been the case in earlier times, as evidenced by the use of chert at Gardom's Edge during the Mesolithic (Barnatt et al. 2002). In comparison, only one pottery sherd from the White Peak material analysed in this study contains inclusions that can be ascribed geologically to the Dark Peak. This imbalance could be used, albeit tentatively, as evidence to support the core-periphery model of Hawke-Smith $(1979,1981)$. The case becomes stronger if the widespread basic igneous tempered ceramics are considered to have been produced close to the primary outcrops of basalt and dolerite, rather than being made at multiple locations by mixing local clay deposits with temper transported various distances from source.

An important consideration in our view of the prehistoric settlement and societal structure of the Peak District is the degree to which this upland area was connected to the outside world, or isolated from it. Barnatt (1999) and others saw the prehistoric Peak District as having a discrete identity from neighbouring regions. Kitchen (2000, 318-319) on the other hand recommended that it should not be viewed as a separate entity, but instead incorporated into a wider area that encompasses neighbouring regions. He cited the presence of axes from distant sources in present day Cumbria, as 
well as the Yorkshire influences apparent in the Food Vessel tradition of the Peak District as evidence that the inhabitants of this area maintained links beyond their region.

If the results of the present study are compared to data on the composition and technology of pottery from other sites in the adjacent counties, evidence may exist for the incorporation of the Peak District into the wider prehistoric world. The tradition of basic igneous tempering that is so prevalent in our dataset seems to be part of a trend that encompasses several parts of northern England, Wales and Ireland (McCorry 1977; Sheridan 1997; Williams and Jenkins 1999). This may suggest the transfer of knowledge and skill across a very large area. Alternatively, it could simply be a function of the suitability of basic igneous rock as a temper material, as well as its availability as primary outcrops or within glacial deposits. Acid and intermediate igneous material obtained from secondary sources is also a common temper type in British prehistory (Freestone and Middleton 1991; Wardle 1992; Rigby 2004), perhaps suggesting a more general preference for hard crystalline rock rather than a specific variety.

With the possible exception of the acid igneous inclusions detected in six sherds from Dark Peak sites, all raw materials that were used to manufacture the ceramics analysed in this study appear to have been obtained from within the Peak District. Evidence for the transport of ceramics or raw materials out of the region is also absent in analysed prehistoric assemblages immediately to the east and west. An exception is an Early-Middle Iron Age vessel excavated from the site of Mellor in Cheshire (Ixer 2005), which may have been made by the addition of vesicular basalt temper from a source in the White Peak (Cumberpatch 2005). Notwithstanding this find, and the supra-regional trend for the use of igneous rock described above, the prehistoric ceramics of the Peak District seem to be unified by their composition and technology, and clearly distinguished from adjacent material. This situation may provide support for the discrete 
Peak District identity postulated by Barnatt (1999) rather than the incorporation of the region into a broader cultural sphere (Kitchen 2000, 318-319). This community may have defined itself by the clearly-demarcated geological and topographic boundaries of the region.

The rise of hillforts and the sudden decline in monument building in the Peak District at the end of the Bronze Age has been interpreted as signalling a distinct change in the nature of prehistoric settlement and society. A different territorial subdivision of the landscape may have developed, with the establishment of a more hierarchical society ruled by elite groups (Barnatt 1999; Barnatt and Smith 2004, 40). This is a point on which most researchers agree; for example Kitchen (2000, 310-318) sees the maintenance of pasture in response to climatic deterioration as leading to a restructuring of the landscape, greater political centralisation and the creation of a sedentary society. The broad dates assigned to the prehistoric ceramics in our dataset means that is not best placed to test the above ideas, however certain comparisons can be made. Despite the overall homogeneity of the material, some differences exist between the EBA-MBA and LBA-EIA sherds in terms of their composition, distribution and possible provenance. The most striking of these is the increase in the use of often non-local basic igneous rock for the production of ceramics in the later period and the corresponding reduction in the use of other temper types such as grog, sandstone and chert. This has been taken above to indicate increased mobility and/or interaction in the LBA-EIA compared to the EBA-MBA, certainly for the inhabitants of the Dark Peak. Such an interpretation clearly conflicts with the proposed territorial restructuring and increased sedentism of the LBA-EIA. However, tighter control of the landscape and its natural resources by elite groups could have also had a similar effect on the prehistoric ceramic assemblage of this period, especially if raw materials such as the prized basic igneous 
rock, or perhaps ceramics made from it, were centrally distributed. Stylistic links between the LBA-EIA pottery of settlements such as Gardom's Edge and Swine Sty and the hillfort of Mam Tor (Barnatt 1999; Barnatt and Smith 2004, 45) may point to the latter. However, the use of local clay deposits and the discovery of possible unused basic igneous temper at several sites including Gardom's Edge seem to rule this out.

\section{CONCLUDING REMARKS}

Detailed scientific analysis of the ceramic paste used to manufacture a large dataset of Early Bronze Age to Early Iron Age pottery from various sites across the Peak District National Park and its comparison with raw material field samples, has shed important new light on the nature of prehistoric society in this region, particularly in terms of settlement patterns and the mobility of its prehistoric inhabitants, as well as their interaction with one another and the outside world. By testing the validity of several competing theories that were established using other archaeological evidence, we can paint a picture of life in this region during the first to third millennia $\mathrm{BC}$.

The widespread utilisation of basic igneous rock from isolated outcrops on the limestone plateau of the White Peak for use as temper in EBA-MBA and LBA-EIA ceramics suggests that this landscape zone may have been of particular importance in prehistory and could perhaps have represented the core of habitation (Hawke-Smith 1979, 1981). However, the undisputed existence of ritual monuments and field systems on the higher ground of the Dark Peak signify that it was also intensively inhabited for several millennia rather than simply acting as a peripheral area (Barnatt 1999; Barnatt and Smith 2004). 
The presence at several sites in the Dark Peak of pottery containing exotic inclusions originating from various sources up to $20 \mathrm{~km}$ from its find spot, as well as possible unused temper material indicates that its inhabitants travelled widely across the region during the Bronze Age (Kitchen 2000) or interacted with other groups to obtain specific favoured resources. Matches between pottery and local clay sources suggests that ceramics were in most cases made close to their find spot. However, the broad compositional and technological connections between the vast majority of sherds analysed in this study, as well as the already reported stylistic connections between the ceramics of certain sites, indicates the presence of a widespread, long-ranging craft tradition. This may have been part of a common identity that was shared by inhabitants of both the White and Dark Peak, particularly in the LBA-EIA.

Despite the presence of igneous tempered ceramics at various sites in the north of England, Wales, and as far away as Ireland, the prehistoric people inhabiting the Peak District do not appear to have been well connected to the outside world. Ceramics containing material derived from the geological limits of Peak District are rare at sites in the adjacent regions, and vice versa. This suggests the existence of an inward looking prehistoric population (Barnatt 1999) rather than the incorporation of the region into a broader cultural sphere (Kitchen 2000, 318-319).

The ceramic evidence for a more hierarchical society and greater territorial subdivision of the land in the Early Iron Age Peak District is not conclusive, as the data recorded in the present study could be interpreted in several ways.

The present study demonstrates the value of detailed compositional and technological analysis of fragmentary prehistoric sherds for the interpretation of resource procurement, craft production, settlement patterns, movement of people and their interaction with one another. In this respect, the well-established technique of thin section 
ceramic petrography, first applied to British prehistoric pottery over 50 years ago (e.g. Cornwall and Hodges 1964), still remains relevant in areas with varied geology, especially when applied to well formulated research questions constructed using other archaeological evidence (Quinn 2013, 122-129).

\section{ACKNOWLEDGEMENTS}

The research presented in this paper forms part of a doctoral thesis completed at University of Sheffield, Department of Archaeology under the supervision of Patrick Quinn, Paul Halstead, and Mike Parker Pearson. Funding was kindly provided via a University of Sheffield Hossein Farmy Endowed Scholarship. John Barnatt and Pauline Beswick, both archaeologists for the Peak District National Park Authority, provided important guidance and insights throughout the project for which they are gratefully acknowledged. Access to artefacts from a range of key sites was permitted by the kind assistance of Gill Woolrich of National Museums Sheffield and Clive Waddington of Archaeological Research Services, Bakewell. All scientific samples analysed in this study are housed at the Institute of Archaeology, University College London.

\section{REFERENCES}

Ainsworth, S., and Barnatt, J., 1998, A Scarp-Edge Enclosure at Gardom's Edge, Baslow, Derbyshire, Derbyshire Archaeological Journal, 118: 5-23. 
Aitkenhead, N., and Waters, C. N., 2002. Dinantian. in The Pennines and Adjacent Areas (eds. N. Aitkenhead, W. J., Barclay, A. Brandon, R. A. Chadwick, J. I. Chisholm, A. H. Cooper, and E. W. Johnson), 37—57, British Geological Survey, Nottingham.

Armstrong, A. L., 1956, Palaeolithic, Neolithic and Bronze Ages. in Sheffield and its Region: A Scientific and Historical Survey (ed. D. L. Linton), 90-110, British Association for the Advancement of Science, Sheffield.

Arnold, D. E., 1985, Ceramic Theory and Cultural Process, Cambridge University Press, Cambridge.

Barnatt, J., 2000, To Each Their Own: Later Prehistoric Farming Communities and their Monuments in the Peak, Derbyshire Archaeological Journal, 120: 1-86.

Barnatt, J., 1999, Taming the Land: Peak District Farming and Ritual in the Bronze Age, Derbyshire Archaeological Journal, 119: 19-78.

Barnatt, J., 1994, Excavations of a Bronze Age Unenclosed Cemetery, Cairns and Field Boundaries at Eaglestone Flat, Curbar, Derbyshire, 1984, 1989-90., Proceedings of the Prehistoric Society, 60: 287-367.

Barnatt, J., and Smith, K., 2004, The Peak District, B.T. Batsford Ltd., London. 
Barnatt, J., and Collis, J., 1996, Barrows in the Peak District. Recent Research. Bookcraft Ltd. Somerset.

Barnatt, J., Bevan, B., and Edmonds, M., 2002, Gardom's Edge: A landscape through time, Antiquity, 76: $51-56$.

Barrett, J. C., 1980, The Evolution of Later Bronze Age Settlement, in Settlement and Society in the British Later Bronze Age, Volume 1 (eds. J. C. Barrett and R. Bradley), 77-100, British Archaeological Report, British Series, 83.

Barrett, J. C., 1979, The Pottery, in Excavation of the Hill Fort of Mam Tor, Derbyshire 1965-69 (eds. D. G. Coombs and F. H. Thompson), Derbyshire Archaeological Journal, 99: 44-49.

Bateman, T., 1861, Ten Years Diggings in Celtic and Saxon Grave Hills, in the Counties of Derby, Stafford and York from 1848 to 1858, J. R. Smith, London.

Bateman, T., and Glover, S., 1848, Vestiges of the Antiquities of Derbyshire, and the Sepulchral Usages of its Inhabitants from the Remote Ages up to the Reformation, John Russell Smith, London.

Brandon, A., 2002, Neogene and Quaternary, in The Pennines and Adjacent Areas. Fourth Edition (eds. N. Aitkenhead, W. J. Barclay, A. Brandon, R. A. Chadwick, J. I. 
Chisholm, A. H. Cooper and E. W. Johnson), 86-119, British Geological Survey, Nottingham.

Champion, T., 2002, The Later Bronze Age, in The Archaeology of Britain, $4^{\text {th }}$ Edition (eds. J. Hunter and I. Ralston), 95-112, Routledge, London.

Cornwall, I. W., and Hodges, H. W. M., 1964, Thin sections of British Neolithic Pottery. Windmill Hill: A Test Site, Bulletin of the Institute of Archaeology, 4: 29-33.

Coombs, D. G., and Thompson, F. H., 1979, Excavation of the Hill Fort of Mam Tor, Derbyshire 1965-69, Derbyshire Archaeological Journal, 99: 7-51

Cumberpatch. C. G., 2005, Mellor: A Review of the Later Prehistoric Ceramics, in Mellor: Living on the Edge. A Regional Study of an Iron Age and Romano-British Upland Settlement (M. Nevell and N. Redhead), 35-43, Manchester Archaeological Monographs Volume 1., University of Manchester Field Archaeology Centre and Mellor Archaeological Trust, Manchester.

Fowler, M. A., 1955, The Transition from Late Neolithic to Early Bronze Age in the Peak District of Derbyshire and Staffordshire, Derbyshire Archaeological Journal, 75: 66122.

Freestone, I. C., and Middleton, A. P., 1991, Report on the petrology of pottery from Iron Age cemeteries at Rudston and Burton Fleming. in Iron Age cemeteries in East 
Yorkshire: Excavations at Burton Fleming, Rudstone, Garton-on- the-Wolds, and Kirkburn (ed. I. M. Stead), 162-164, English Heritage Archaeological Report 22. English Heritage in association with the British Museum, London.

Guilbert, G., and Vince, A., 1996, Petrology of Some Prehistoric Pottery from Mam Tor, Derbyshire Archaeological Journal, 116: 49-59.

Harrad, L. J., 2004, Gabbroic Clay sources in Cornwall: A Petrographic Study of Prehistoric Pottery and Clay Samples, Oxford Journal of Archaeology, 23: 271-286.

Hawke-Smith, C. F., 1979, Man-land Relations in Prehistoric Britain: The Dove-Derwent Interfluve, Derbyshire. A Study in Human Ecology, British Archaeological Reports, British Series, 64, Oxford.

Hawke-Smith, C. F., 1981, Land Use, Burial Practice and Territories in the Peak District c. 2000-1000 BC., in Prehistoric Communities in Northern England (ed. In, G. Barker, G.), 57-72, Department of Prehistory and Archaeology, University of Sheffield.

Heizer, R. F., and Treganza, A. E., 1972, Mines and Quarries of the Indians of California, Ballena Press, Ramona, California.

Hicks, S. P., 1971, Pollen Analytical Evidence for the Effect of Prehistoric Agriculture on the Vegetation of North Derbyshire, New Phytologist, 70: 647-667. 
Ixer, R., 2005, Petrographic Analysis of the Vessel from OVM 01 Trench 15, Context 021. in Mellor: Living on the Edge. A Regional Study of an Iron Age and Romano-British Upland Settlement (M. Nevell and N. Redhead), 39-40, Manchester Archaeological Monographs Volume 1, University of Manchester Field Archaeology Centre and Mellor Archaeological Trust, Manchester.

Kitchen, W. H., 2000, Later Neolithic and Bronze Age Land Use and Settlement in the Derbyshire Peak District: Cairnfields in Context, Ph.D. thesis, Department of Archaeology. University of Sheffield.

May, M., and Tuckson, M., 2000, The Traditional Pottery of Papua New Guinea, Crawford House, Adelaide.

McCorry, M., 1977, A Petrological Analysis of Lyles Hill Pottery, Irish Archaeology Research Forum, 4: 9-12.

Michelaki, K., Braun, G. V., and Hancock, G. V., 2014, Local clay sources as histories of human-landscape interactions: a ceramic taskscape perspective, Journal of Archaeological Method and Theory, 22: 783-827.

Parker-Pearson, M., 2002, The Earlier Bronze Age. in The Archaeology of Britain, $4^{\text {th }}$ Edition, (eds. J. Hunter and I. Ralston), 77-94, Routledge, London.

Parker Pearson, M., 2005, Bronze Age Britain, B.T. Batsford, London. 
Peacock, D. P. S., 1988, The Gabbroic Pottery of Cornwall, Antiquity, 62: 302-304.

Quinn, P. S., 2013, Ceramic Petrography: The Interpretation of Archaeological Pottery \& Related Artefacts in Thin Section, Archaeopress, Oxford.

Quinn, P. S., Burton, M., 2009. Ceramic petrography and the reconstruction of huntergatherer craft technology in Late Prehistoric Southern California. in Interpreting Silent Artefacts (ed. Quinn, P. S), 267-295., Archaeopress, Oxford.

Rigby, V., 2004, Pots in Pits. The British Museum Settlement Project 1988-92, East Riding Archaeologist, 11.

Rye, O. S., 1976, Keeping Your Temper under Control: Materials and the Manufacture of Papuan Pottery, Archaeology \& Physical Anthropology in Oceania, 11: 106-137.

Sheridan, A,. 1997, Pottery Production in Neolithic and Early Bronze Age Ireland: A Petrological and Chemical Study, Recent Developments in Ceramic Petrology (eds. A. Middleton and I. Freestone), 305-336, British Museum Occasional Paper, 81, British Museum Press, London.

Tite, M. S., 1999, Pottery production, distribution and consumption: The contribution of the physical sciences, Journal of Archaeological Method and Theory, 6: 181-233. 
Vince, A., 1998, The petrology of a Trevisker ware vessel from Monkton, Thanet, Kent. Alan Vince Archaeological Consultancy, Scientific Report, 1998/023.

Wardle, P., 1992, Earlier Prehistoric Pottery Production and Ceramic Petrology in Britain. British Archaeological Reports, British Series, Oxford, 225.

Williams, J., and Jenkins, D., 1999, A Petrographic Investigation of a Corpus of Bronze Age Cinerary Urns from the Isle of Anglesey, Proceedings of the Prehistoric Society 65: $189-221$.

Woodward, A., 2008, Ceramic Technologies and Social Relations, in Prehistoric Britain (ed. J. Pollard), 288-309, Blackwell Publishing, Oxford. 


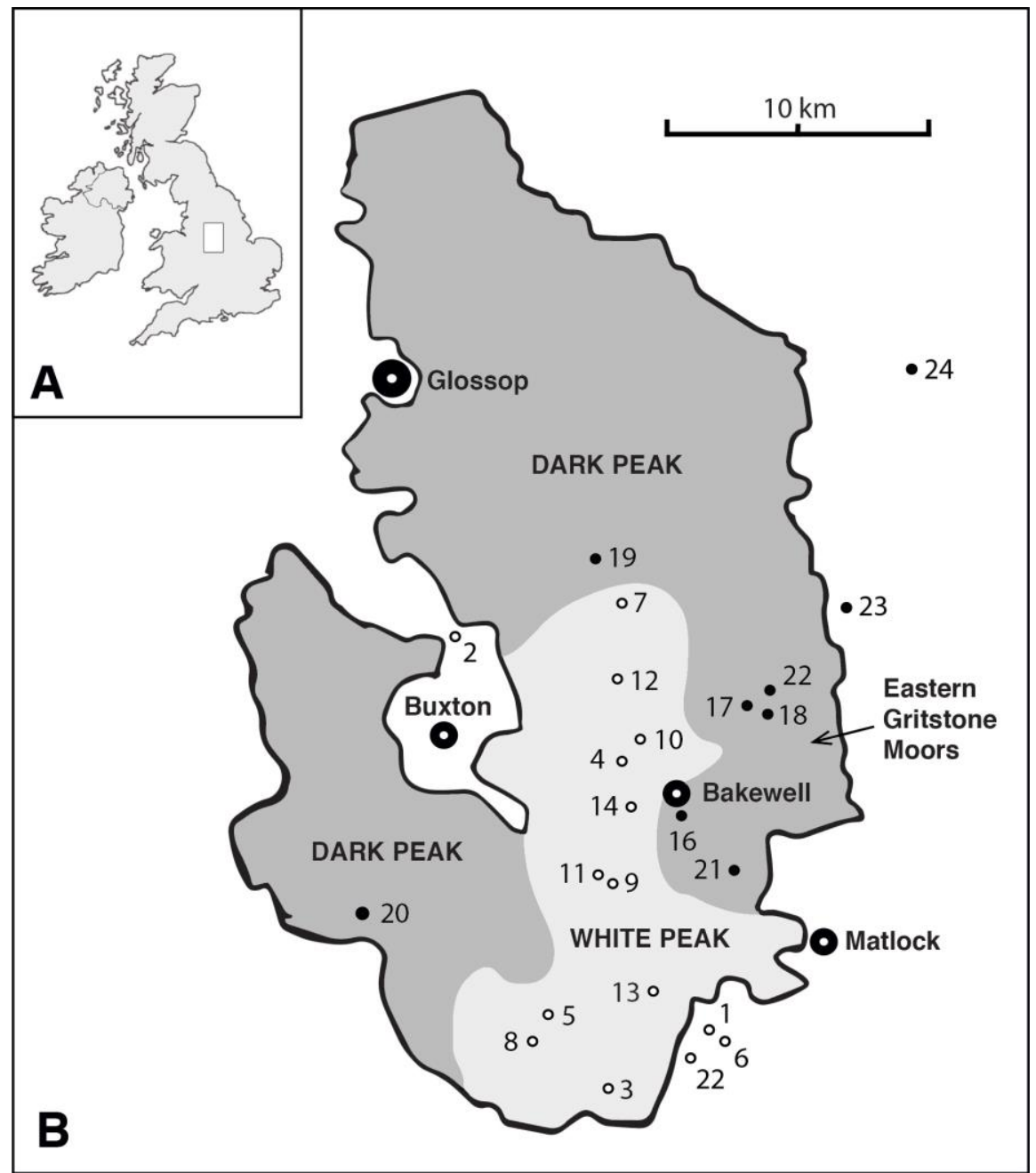

Figure 1. Location of the Peak District National Park at the southern end of the Pennine chain of northern Britain, A. Boundaries of the National Park with two main landscape zones and present day settlements and archaeological sites, B. Key to sites: White Peak (open circles) 1. Carsington Pasture, 2. Cow Low, 3. Dove Dale Thorpe Cloud, 4. Fin Cop, 5. Gratton Hill, 6. Harborough Rocks, 7. Hartle Moor, 8. Illam Moor, 9. Kenslow, 10. Monsal Dale Hay Top, 11. One Ash, 12. Rolley Low, 13. Roystone Grange, 14. Sheldon, 15. Wigber Low; Dark Peak (closed circles) 16. Ball Cross, 17. Eaglestone Flat, 18. Gardom's Edge, 19. Mam Tor, 20. Roaches, 21. Stanton Moor, 22. Swine Sty, 23. Totley Moor, 24. Bailey Hill. 


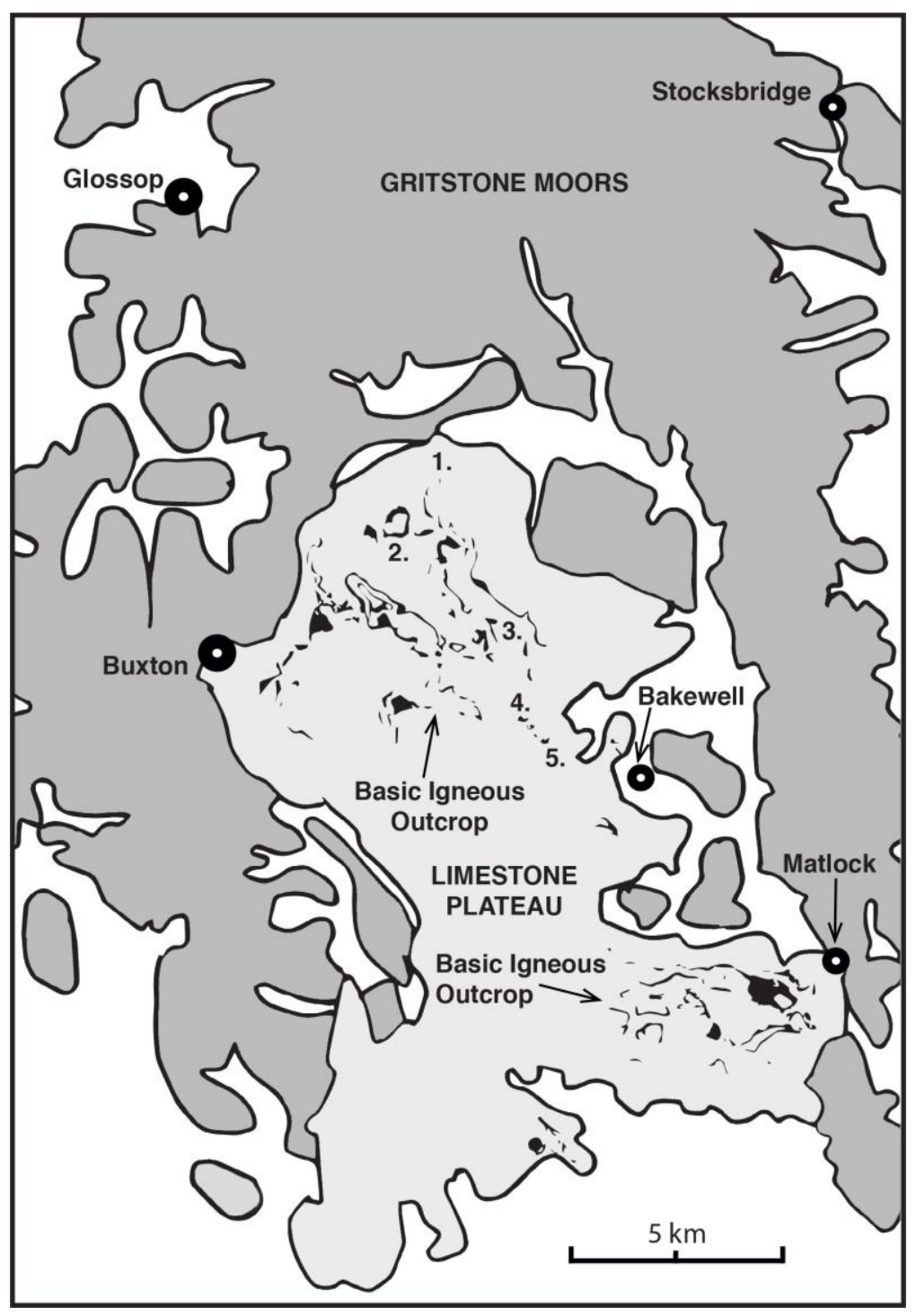

Figure 2. General geological map of the Peak District National Park with selected raw material sampling sites indicated: 1. Cave Dale, 2. Peak Forest, 3. Tideswell, 4. Wye Valley, 5. Black Rock Corner. Based on Aitkenhead, et al. (2002, 35) and Barnatt and Smith $(2004,13)$. 

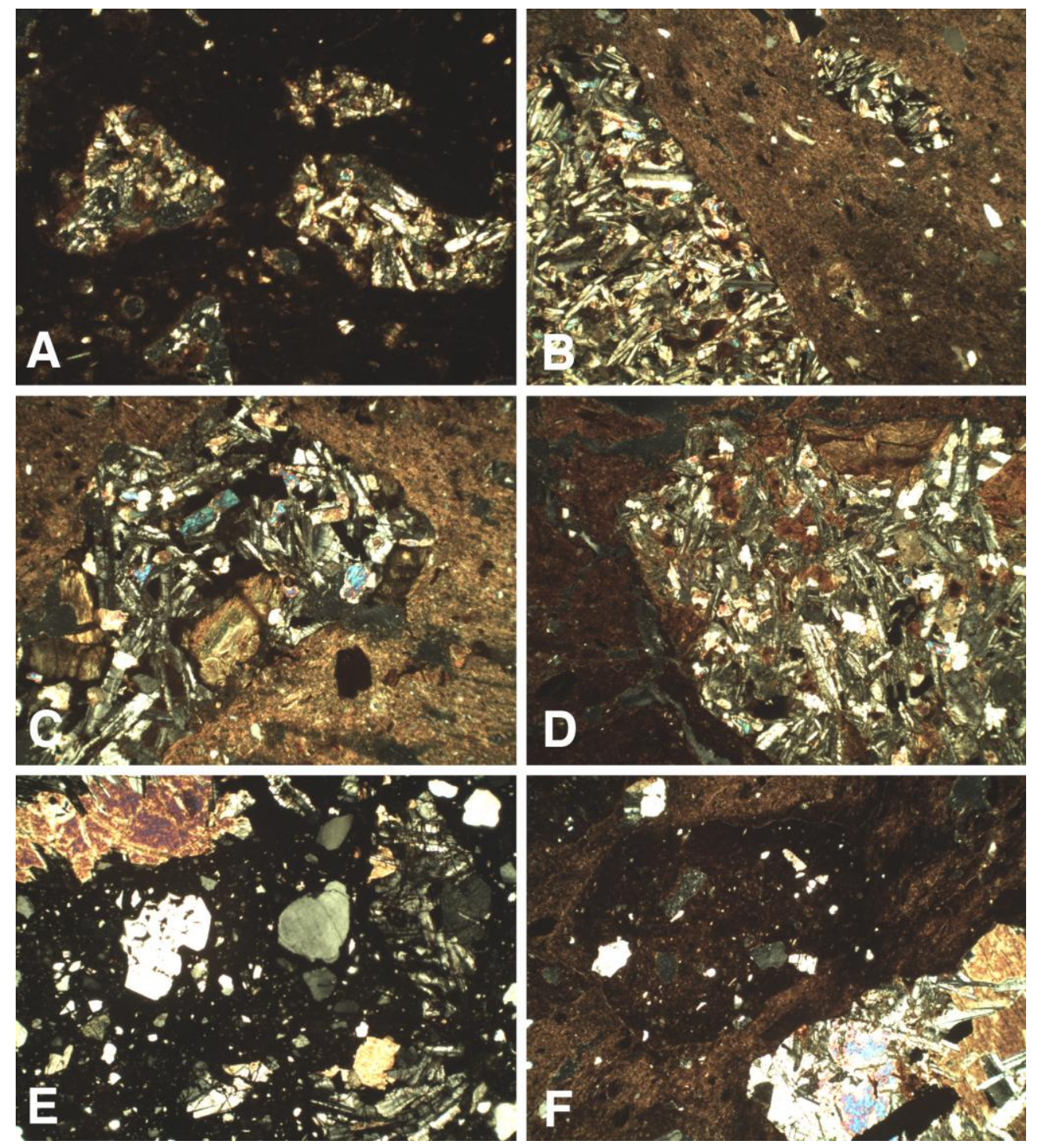

Figure 3. Thin section photomicrographs of selected prehistoric pottery sherds from the Peak District National Park analysed in this study. A. Fabric 1, Sample Gardom's Edge 1; B. Fabric 1, Sample Ball Cross 20; C. Fabric 1, Sample Gardom's Edge 23; D. Fabric 1, Sample Mam Tor 40; E. Fabric 2, Sample Fin Cop 9; F. Fabric 3, Sample Eaglestone Flat 3. All images taken in crossed polars. Image width $=2.9 \mathrm{~mm}$. 

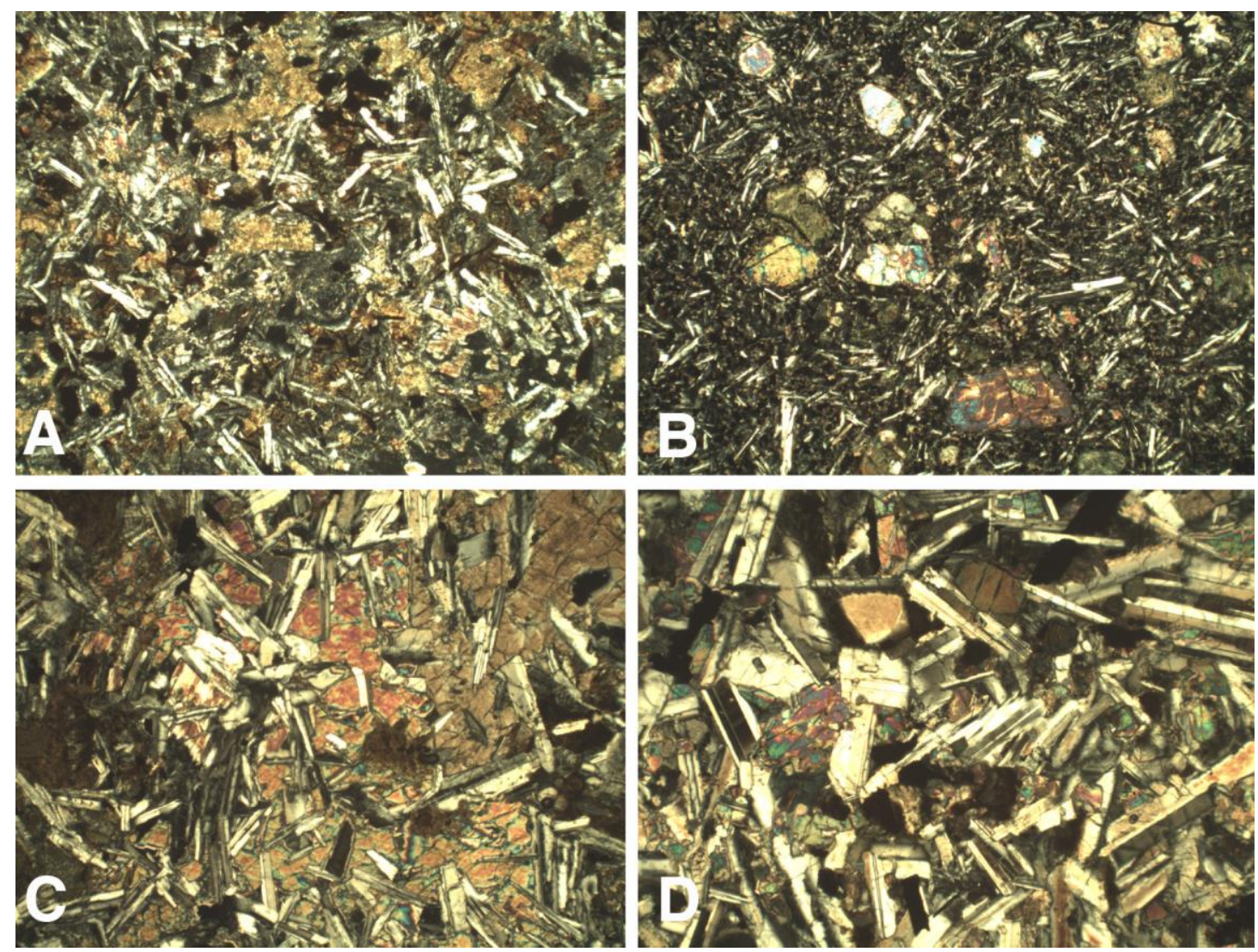

Figure 4. Thin section photomicrographs of selected basic igneous field samples collected from the Peak District National Park in this study. A. Equigranular olivine rich basalt from Black Rock Corner, B. Porphyritic olivine-rich basalt from Calton Hill, C. Dolerite with ophitic texture from Ible Quarry, D. Equigranular dolerite from Waterswallows Quarry. All images taken in crossed polars. Image width $=2.9 \mathrm{~mm}$. 

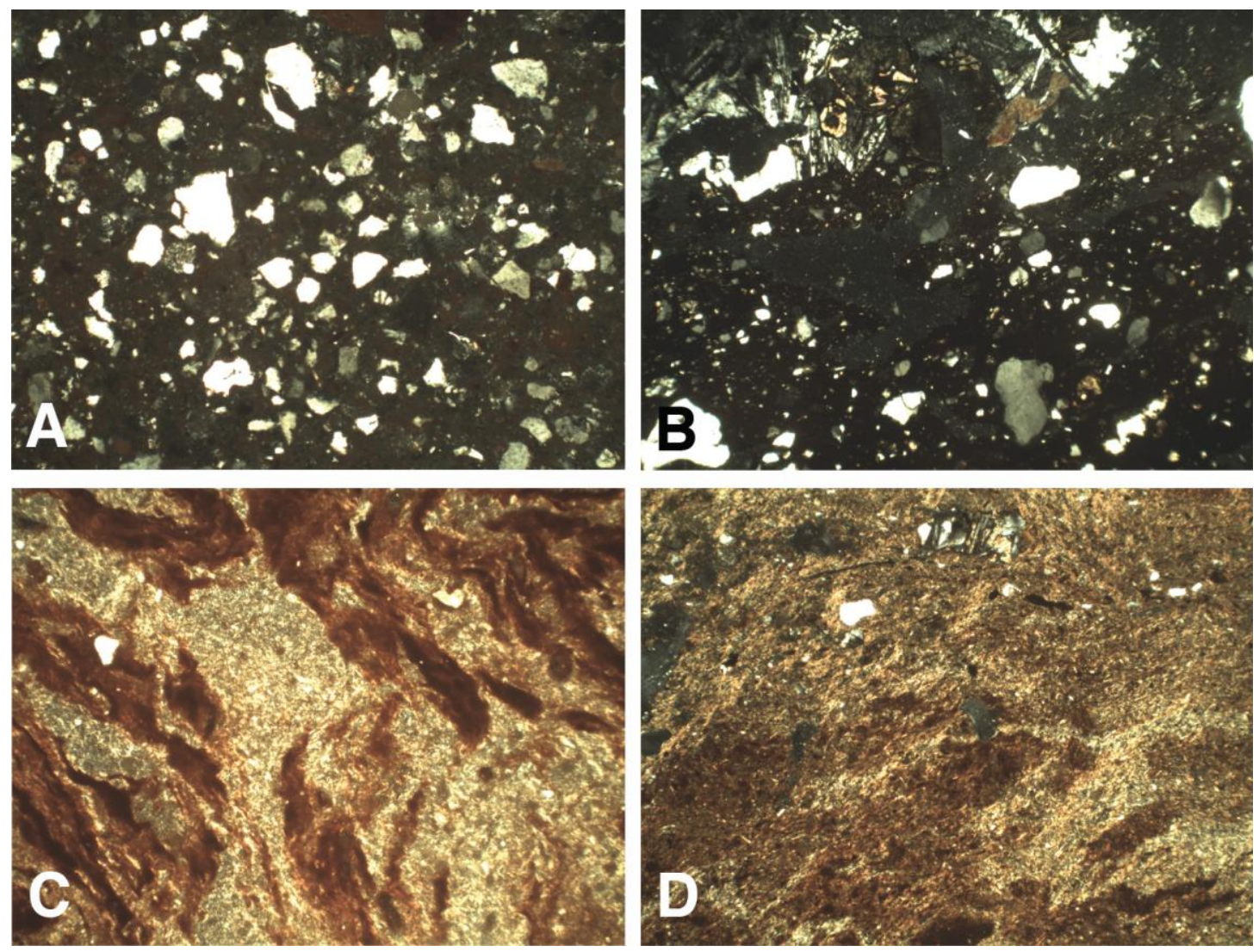

Figure 5. Thin section photomicrographs of petrographic matches between clay-rich

field samples and the clay used to manufacture prehistoric pottery sherds from the Peak District National Park. A. Sandy clay source from the Wye Valley near the hillfort of Fin Cop. B. Basic igneous tempered ceramic from Fin Cop with sandy base clay. C. Variegated clay source from the Gardom's Edge. D. Basic igneous tempered ceramic from Gardom's Edge with heterogeneous base clay. All images taken in crossed polars. Image width $=2.9 \mathrm{~mm}$. 

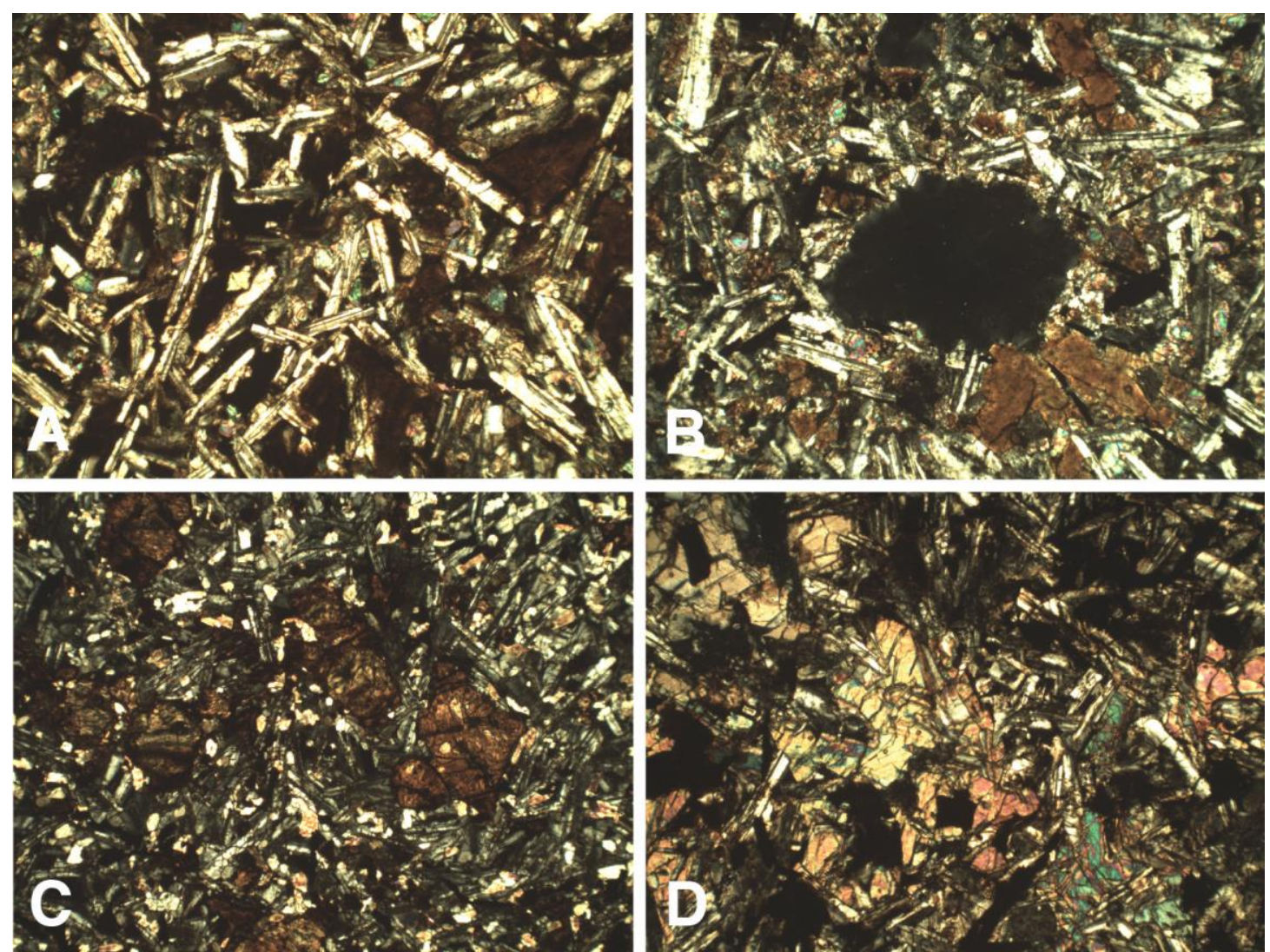

Figure 6. Thin section photomicrographs of fragments of basic igneous rock excavated from the sites of Fin Cop and Gardom's Edge and initally identified as daub'. A. Dolerite from Fin Copp, B. Vesicular basalt from Fin Copp, C. Porphyritic basalt from Gardom's Edge, D. Dolerite with ophitic texture from Gardom's Edge. All images taken in crossed polars. Image width $=2.9 \mathrm{~mm}$. 


\begin{tabular}{|c|c|c|c|c|c|}
\hline Archaeological Site & Type & $\begin{array}{l}\text { Lanscape } \\
\text { Zone }\end{array}$ & $\begin{array}{l}\text { Sherd } \\
\text { s }\end{array}$ & Period & $\begin{array}{c}\text { Basic Igneous } \\
(\%)\end{array}$ \\
\hline Carsington Pasture & Barrow & White Peak & 1 & EBA-MBA & 0 \\
\hline Cow Low & Barrow & White Peak & 1 & EBA-MBA & 100 \\
\hline Dove Dale Thorpe & & & & & 0 \\
\hline Cloud & Barrow & White Peak & 1 & EBA-MBA & \\
\hline Fin Cop & Hillfort & White Peak & 12 & LBA-EIA & 100 \\
\hline Gratton Hill & Barrow & White Peak & 1 & EBA-MBA & 0 \\
\hline Harborough Rocks & Settement & White Peak & 7 & EBA-MBA & 100 \\
\hline Hartle Moor & Barrow & White Peak & 1 & EBA-MBA & 0 \\
\hline Illam Moor & Barrow & White Peak & 1 & EBA-MBA & 0 \\
\hline Kenslow & Barrow & White Peak & 1 & EBA-MBA & 100 \\
\hline Monsal Dale Hay & & & & & 0 \\
\hline Top & Barrow & White Peak & 1 & EBA-MBA & \\
\hline One Ash & Barrow & White Peak & 1 & EBA-MBA & 0 \\
\hline Rolley Low & Barrow & White Peak & 1 & EBA-MBA & 0 \\
\hline Roystone Grange & Settement & White Peak & 9 & LBA-EIA & 77 \\
\hline Sheldon & Barrow & White Peak & 1 & EBA-MBA & 0 \\
\hline Wigber Low & Barrow & White Peak & 1 & EBA-MBA & 0 \\
\hline & $\begin{array}{l}\text { Defended set- } \\
\text { tlement }\end{array}$ & & & & 80 \\
\hline Ball Cross & & Dark Peak & 20 & LBA-EIA & \\
\hline Eaglestone Flat & Flat Cemetery & Dark Peak & 10 & EBA-MBA & 100 \\
\hline Gardom's Edge & Settement & Dark Peak & 92 & LBA-EIA & 99 \\
\hline Mam Tor & Hillfort & Dark Peak & 50 & LBA-EIA & 80 \\
\hline Roaches & Flat Grave & Dark Peak & 1 & EBA-MBA & 0 \\
\hline Stanton Moor & $\begin{array}{l}\text { Barrow Ceme- } \\
\text { tery }\end{array}$ & Dark Peak & 11 & EBA-MBA & 45 \\
\hline Swine Sty & Settement & Dark Peak & 7 & EBA-LIA & 71 \\
\hline Totley Moor & Ringwork & Dark Peak & 1 & EBA-MBA & 100 \\
\hline Bailey Hill & Barrow & Dark Peak & 1 & EBA-MBA & 0 \\
\hline
\end{tabular}

Table 1. Details of prehistoric archaeological sites from which pottery was analysed in 
this study.

\section{APPENDIX 1 CERAMIC FABRIC DESCRIPTIONS}

\section{FABRIC 1 - BASIC IGNEOUS TEMPER in NON-CALCAREOUS CLAY}

\section{$\underline{\text { Samples }}$}

B1, B3, B4, B5, B7, B9, B10, B13, B14, B16, B18, B19, B20, CL1, E1, E2, E6, E7, E8, E9, G1, G2, G3, G4, G5, G6, G7, G8, G9, G10, G11, G12, G13, G14, G15, G16, G17, G18, G20, G21, G22, G23, G24, G25, G26, G27, G28, G29, G30, G31, G32, G33, G34, G35, G36, G37, G40, G41, G42, G43, G44, G45, G46, G47, G48, G49, G51, G52, G53, G54, G55, G56, G57, G58, G60, G61, G62, G63, G64, G65, G67, G68, G69, G70, G71, G72, G73, G74, G76, G77, G78, G79, G80, G81, G82, G83, G84, G85, G86, G87, G88, G89, G90, G91, G92, G93, G94, G97, HR3, HR6, MT3, MT9, MT10, MT15, MT19, MT23, MT24, MT25, MT26, MT30, MT31, MT34, MT35, MT36, MT38, MT39, MT40, MT42, MT44, MT45, MT46, MT48, MT50, MT52, MT53, RG3, S5, S6, SM7, SM8, SM9, TM1.

\section{$\underline{\text { Inclusions }}$}

10-35\%. el \& eq. a-r. Single to open spaced. Crude alignment to margin of samples. Bimodal (Samples G78, MT31, HR3) to strongly bimodal (Samples CL1, HR6).

\section{Coarse fraction}

\section{$45-70 \%$. 5.6-0.24mm.}

Predominant-few: Dolerite; el \& eq. a-wr. $<5.6 \mathrm{~mm}$. Mode $1.76 \mathrm{~mm}$. Inclusions can be olivine rich (Samples G28, G83, B4, RG3) or containing only augite and feldspar (Samples G94, B13, HR6). Size of constituent crystals varies greatly within and between samples, with a grain size consistent with basalt in several samples (Samples B13, MT15). Vesicular characteristics are rare but are present (Samples G23, MT50, E9, SM9, TM1). Variation in grain size is common both between and within individual sherds (Sample MT36) with fine grained basalt also occurring (Samples G94, MT15, MT36). Partial replacement by precipitated silicate mineral in seen in two sherds (Sample MT30), being amygdaloidal in the latter. Feldspars are almost exclusively lath shaped, simply twinned and randomly orientated, although zoning is present in a few samples (Samples B9, MT23), as is partial flow (Samples B19, G57, MT10) and extensive flow (Samples B3, B13). Olivine crystals are almost exclusively subhedral, although anhedral constituents are rarely seen (Sample G1), as are anhedral crystals (Sample B13). Sub-ophitic texture in which the feldspars are partially enclosed by augite crystals is common (Samples G18, G87, MT30, B5, HR6, RG3). The majority of constituent minerals are equigranular, although exceptions are noted with the feldspars (Samples B14, E2, G37, MT30) and olivine's (Sample G70). Virtually all basic inclusions have been subject to varying degrees of weathering with only a few sherds containing un-weathered inclusions (Samples G15, MT46, B4). The majority of the fabric demonstrates degrees of weathering which affect mostly the larger olivine's (Samples 
B16, G3, G82, MT30) whilst extensive weathering to a deep red colour is also seen (Sample G40). Extreme weathering to a deep red or yellow colour occurs (Sample E1), where all constituent minerals are no longer identifiable with the exception of a few relic feldspars (Samples MT25, MT45, MT48, MT50). Other forms of weathering include the reduction of the basic igneous to a clay brown colour with a few visible relic feldspars (Sample SM9).

dominant-absent: Shale; el \& eq. sa-sr. $<2.80 \mathrm{~mm}$. Mode $=0.88 \mathrm{~mm}$. Contain sa-sr quartz (Samples G2, G14, G51, MT9, TM1).

common-few: Quartz; el \& eq. a-r. <1.20mm. Mode 0.40mm. Straight and undulose extinction.

common-absent: $T F$ 's; el \& eq. sa-wr. $<2.40 \mathrm{~mm}$. Mode $0.40 \mathrm{~mm}$. Red and brown to very dark brown. High to almost neutral optical activity. Sharp to merging boundaries. Discordant. Composed of optically inactive to active brown clay (some containing subangular to sub-rounded quartz) contained in the fine and coarse fractions, and optically active red clay (Sample E6). Possibly related to the weathering of clay and/or shale to TF's. Clay pellets (Samples B9, G7, G9, MT3) streaks (Samples B20, G11, G13, MT3), and swirls (Samples G25, G33).

few-absent: Polycrystalline quartz; el \& eq. sa-r. $<3.04 \mathrm{~mm}$. Mode $0.56 \mathrm{~mm}$. Some inclusions demonstrate metamorphosed characteristics (Samples G2, MT39).

rare-absent: Chert; el \& eq. a-r. $<2.56 \mathrm{~mm}$. Mode $=0.96 \mathrm{~mm}$. A mixture of weathered (Sample G14) and un-weathered cherts, some of which are iron rich (Samples G14, G15). Radiolarian chert is seen (Sample G2) but chalcedonic chert is more common (Sample G67).

rare-absent: Sandstone; el \& eq. sa-r. $<0.88 \mathrm{~mm}$. A range of quartz rich fragments, ranging from quartz arenite (Samples G3, MT30), sub-arkrose (Samples G8, G43), and quartzwacke (Sample MT30, MT31).

very rare-absent: Feldspars; el \& eq. sa-r. <1.04mm. Mode 0.40mm. Inclusions demonstrate simple twinning.

very rare - absent: Muscovite mica; el. sr. 0.40mm (Sample G90).

very rare-absent: Bone; el. sr. 2.24mm. Species cannot be identified (Sample MT24).

very rare-absent: Weathered calcite; eq. sr. $1.6 \mathrm{~mm}$. Very weathered calcite mineral, attached to a quartz and a feldspar crystal (Sample B7).

$\underline{\text { Fine Fraction }}$

$30-55 \% .0 .24-0.01 \mathrm{~mm}$.

predominant-dominant: Quartz

common-absent: Basic igneous 
few - absent: White mica

rare-absent: Shale

very rare-absent : Olivine

very rare-absent: Biotite mica

very rare-absent: Chert

rare-absent: Polycrystalline quartz

$\underline{\text { Matrix }}$

55-75\%. Non-calcareous. Light yellow brown to light red brown to dark brown in PPL, light yellow brown to brown to dark brown in XP (x40). Clay colour differentiation in several samples (G8, G11, G25, G33) Heterogeneous to moderately homogeneous, possibly related to TF's in some samples. Core margin colour differentiation (Samples G4, G12, G81, B3, HR6, RG3). Optically moderately active (B16, G3, HR3, MT15), to very active (Samples B13, E9, G5, G7, MT3, MT24, S5).

\section{$\underline{\text { Voids }}$}

1-20\%. Consisting mainly of vughs (Samples G4, G30, MT3) and mega vughs (Samples B13, HR6M G31, G46, MT44, MT52), channels (Samples G1, G12) and mega channels (Samples B19, G14, G23, MT25) and vesicles (Samples B5, G8, G29). Crude (Samples G22, G24) to strong alignment (Samples B19, G18, MT39) to margin of samples. Some have blackened margins (Samples G42, G49, G80, G91, MT19), possibly the remains of charred organics. Evidence of coil building is seen in Samples G3, G7, G15, G50, G51, G54, G65, MT52, and E9.

\section{Comments}

This large heterogeneous fabric is characterised by the presence of angular to well rounded, weathered dolerite temper. There is significant variation within the fabric in terms of modal grain size of the coarse fraction, non-plastic inclusions, and degree of weathering of the basic igneous temper. The samples however, do not easily subdivide into different textural sub-fabrics. All ceramics appear to have been produced by the addition of quantities of loose, weathered basic igneous material to non-calcareous clay, containing varying degrees of quartz. The differences inherent in the basic igneous temper and the clays suggest a variety of similar raw material sources were being utilised. High proportions of argillaceous inclusions in samples such as MT30 also indicate that shale sources were utilised. The high optical activity and core margin colour variation which characterises this fabric indicates ceramics fired below $850^{\circ} \mathrm{c}$ in a poorly controlled, oxidising atmosphere.

\section{BASIC IGENOUS SUB-FABRIC 1A}




\section{$\underline{\text { Samples }}$}

B6, G19, G95.

\section{Description:}

These samples differ from the main fabric due to the presence of weathered acid igneous inclusions of Rhyolite within the matrix. Inclusions are el \& eq. sa-sr. Mode $2.00 \mathrm{~mm}$. Additionally Sample B6 contains a single opaque inclusion, being eq \& sr, $4.00 \mathrm{~mm}$, with shrinkage voids. This appears to be a relatively large dried clay inclusion.

Comparison with the main fabric demonstrates similar characteristics and variation in the coarse and fine fractions with the exception of the acid igneous inclusions, and may therefore be the natural variation. The relative homogeneity of the grain size would suggest these inclusions are a natural component of the clay.

\section{BASIC IGENOUS SUB-FABRIC 1B}

Samples:

\section{B17, G66, MT13, MT41, MT49.}

These samples differ from the main fabric due to the lack of quartz in the fine fraction, and virtual absence from the coarse fraction. Other inclusions common in the main fabric are also generally absent, although TF's still occur. In spite of these differences the basic igneous inclusions are consistent with those contained in the main fabric. This sub-fabric may therefore represent highly processed clay which has removed most of the naturally occurring inclusions, or alternatively a separate raw material source.

\section{BASIC IGENOUS SUB-FABRIC 1C}

Samples:

MT4, MT5, MT6, MT8)

\section{Description:}

These samples differ from the main fabric due to the presence large opaque, iron rich inclusions in the clay matrix, some of which appear to be ironstone (Sample MT8). Inclusions are el \& eq. sr. $<5.04 \mathrm{~mm}$. Mode $0.80 \mathrm{~mm}$. Comparison with the main fabric shows similar characteristics and variation in the coarse and fine fractions, and may represent a separate clay source, or natural variation.

\section{BASIC IGENOUS SUB-FABRIC 1D}

\section{$\underline{\text { Samples }}$}


G75, HR1, HR2, HR4, HR5, HR7, MT7, MT14, MT17, MT37, MT55, RG2, RG4, RG5, RG6, RG8, SM10.

\section{Description:}

These samples differ from the main fabric due to the presence of large amounts of subangular to rounded quartz, mostly occurring in the fine fraction. In spite of this difference, the basic igneous inclusions show comparable size and weathering to the main fabric, as with the presence of other inclusions, for instance chert (Sample RG6, RG8), shale (Sample RG2) and coarse sandstone (quartz arenite and muddy sandstone) (Samples G75, RG5). The presence of such quantities of fine quartz in the clay of this subfabric would suggest a different raw material source.

\section{BASIC IGENOUS SUB-FABRIC 1E}

\section{$\underline{\text { Samples }}$}

G96.

\section{Description:}

This sample differs from the main fabric due to the presence of severely weathered basalt which has been partially replaced by the silicate mineral epidote in an amygdaloidal texture $<0.48 \mathrm{~mm}$. This section therefore possibly represents a different raw material source of basalt, although the matrix contains similar characteristics to the main fabric.

\section{BASIC IGENOUS SUB-FABRIC 1F}

\section{$\underline{\text { Samples }}$}

$\mathrm{K} 1$.

This sample differs from the main fabric due to the presence of altered olivine dolerite in which the feldspar laths have been extensively replaced by a precipitated silicate mineral. el \& eq. sa-sr. $<2.4 \mathrm{~mm}$. Mode $1.12 \mathrm{~mm}$. Although partial silicate replacement is observed within the main fabric, this characteristic is unique to Sample K1, therefore suggesting an alternate source for the dolerite. The clay matrix is within the tolerance of the main fabric.

FABRIC 2 - BASIC IGNEOUS AND SAND TEMPER IN NON-CALCAREOUS CLAY

$\underline{\text { Samples }}$

FC1, FC3, FC4, FC6, FC8, FC9, FC12, FC14.

$\underline{\text { Inclusions }}$ 
20-35\%. el \& eq. sa-r. Open spaced, single spaced or less. No alignment to crude alignment (FC9, FC12) to margins of sample. Bimodal grain size distribution in all samples.

\section{Coarse Fraction}

$60-80 \%, 7.2 \mathrm{~mm}-0.24 \mathrm{~mm}$.

predominant-dominant: Dolerite; sa-sr. eq \& el. Maximum grain size $<7.2 \mathrm{~mm}$. Mode $2.4 \mathrm{~mm}$. Crystals of augite partially enclose twinned, lath shaped crystals of plagioclase feldspar in a sub-ophitic texture, demonstrating no flow. Dolerite is generally un-weathered and with a texture dominated by augite. Generally weathered dolerite inclusions occur in FC1, FC4 and FC12, whilst one fresher inclusion in FC14 contains a large phenocryst of twinned, lath shaped plagioclase feldspar.

frequent: Quartz; eq \& el. sa-wr. $<0.8 \mathrm{~mm}$. Mode $0.32 \mathrm{~mm}$. Straight or undulose extinction.

few-very rare: $T F$ 's; eq. sr-wr. $<0.56 \mathrm{~mm}$. Mode $0.24 \mathrm{~mm}$. Dark brown to brown. Neutral optical activity. Sharp boundaries, possibly clay pellets. Concordant to discordant. Samples FC3, FC4, FC6, FC8, FC9, FC12.

few-absent: Shale; eq \& el. sr-r. $<2.64 \mathrm{~mm}$. Mode $1.2 \mathrm{~mm}$. Light brown to mid brown in colour. Demonstrates characteristic lamination. Samples FC4, FC6, FC12, FC14.

very rare-absent: Chert; el. sa-sr. <1.6mm. Samples FC1, FC3, FC6. One sa chert inclusion in $\mathrm{FC} 1$ is unusually brown in colour with some dark brown banding.

very rare-absent: Biotite mica; el. sa-sr. 0.48mm. Sample FC6.

very rare-absent: Quartz arenite; eq. sa-sr. $<0.80 \mathrm{~mm}$. Mean $0.40 \mathrm{~mm}$. Sample FC8.

very rare-absent: Microcline; eq. $0.48 \mathrm{~mm}$. Single altered inclusion in FC3.

very rare-absent: Mudstone; eq. r. <1.6mm. Samples FC6 and FC14.

very rare-absent: Plagioclase feldspar; eq. sr. 0.32mm. Sample FC4.

$\underline{\text { Fine Fraction }}$

$20-40 \% .0 .24-0.01 \mathrm{~mm}$.

predominant: Quartz.

few - very rare: White mica.

very rare- absent: Plagioclase feldspar.

very rare-absent: Basic igneous 
very rare-absent: Chert

very rare-absent: Quartz arenite

very rare-absent: Polycrystalline quartz

\section{$\underline{\text { Matrix }}$}

60-75\%. Non calcareous. In PPL (x40) colour ranges from a light yellow to very dark brown in all samples except FC1, where the colour is very dark brown throughout. In $\mathrm{XP}$ colour varies from dark brown to mid brown in FC1, to light yellow brown at the margins, to dark brown at the core of all other samples. Core margin colour differentiation occurs in all samples except FC1. Optical activity ranges from none in FC1 to moderate optical activity in FC3, FC4, FC6, and FC12, to a high level of optical activity in FC9 and FC14.

\section{$\underline{\text { Voids }}$}

2-20\%. Consisting of mega-vughs and channels (FC4, FC6, FC12, FC14), meso-channels (FC7, FC9) and meso and micro-vesicles in all samples. Poor (FC3, FC6, FC8) to strong (FC9, FC14) alignment to margin of sections. Orientation of voids in FC1 possibly relates to coil structure.

\section{Comments}

This homogeneous fabric is characterised by the presence of generally sub-angular to sub-rounded, un-weathered dolerite, and rounded sand temper in non-calcareous clay. There is some variation within the fabric and sub-fabric, mainly consisting of the presence of shale inclusions in samples FC4, FC6, FC12, and FC14, which are not present in other samples. The dolerite temper shows little variation, being characterised by a high level of augite partially enclosing lath shaped plagioclase feldspars in a sub-ophitic texture. This suggests a single source was utilised for the temper, probably originating from an exposure which has undergone little weathering. All samples appear to have been produced by the addition of loose fragments of dolerite collected from a single source, and also sand rounded by the action of water.

The uniformity of the fine fraction suggests a single clay source for this fabric and subfabric. Of notable significance is the presence of weathered acid igneous rock in samples FC5, FC10, FC11, FC13, forming the sub-fabric. These inclusions are known to occur naturally within the boulder clays of the area, in addition to small amounts of chert and other material, possibly indicating a source nearer to the site, such as the boulder clays around Bakewell.

The optical activity of many of the sherds indicate a relatively low firing temperature, whilst the colour variation suggests an atmosphere which was relatively uncontrolled, producing sherds which were both oxidised and reduced. The orientation of voids in FC1 suggests ceramics which were coil built. This fabric matches the main 'Basic igneous tempered' group in the composition of the dolerite temper, although there is far less variation in the latter. The main differences which set this fabric apart are the presence of sand rounded sand and the presence of large acid igneous inclusions. 


\title{
BASIC IGNEOUS AND SAND TEMPERED SUB-FABRIC 2A
}

\author{
$\underline{\text { Samples }}$
}

FC5, FC10, FC11, FC13.

These samples differ from the main fabric due to the presence of acid igneous inclusions of Rhyolite within the matrix. Inclusions are el \& eq. sa-sr. $<6.0 \mathrm{~mm}$. Mode $2.24 \mathrm{~mm}$. Some inclusions are weathered in FC10 and FC11, occurring in greater size and abundance in FC11. Measuring 4.48mm, one sa, el, amorphous weathered inclusion in FC5 is composed of silica and alkali feldspar, possibly representing an altered acid igneous.

Comparison with the main fabric shows similar characteristics and variation in the coarse and fine fractions with the exception of the acid igneous inclusions, and may therefore be natural variation within the fabric. It is difficult to tell if the acid igneous were added deliberately as temper, although the only occurrence of such rock types within the Peak District is as natural components of boulder clay.

\section{FABRIC 3 - BASIC IGNEOUS AND GROG IN NON-CALCAREOUS CLAY}

$\underline{\text { Samples }}$

B12, E3, E4, E5, E10, HM1, MT2, MT54, S1, S2, S7, SM11.

$\underline{\text { Inclusions }}$

15-35\%. el \& eq. a-sr. Single spaced or less. Crude (B12, S7) to strong alignment (E11) to margin of samples. Highly bimodal grain size distribution (Samples B1, E5, MT2).

\section{Coarse Fraction}

$40-80 \% .5 \cdot 6-0.24 \mathrm{~mm}$.

predominant-rare: Grog; el \& eq. sa-r. $<4.56 \mathrm{~mm}$. Mode $1.76 \mathrm{~mm}$. Composed of light mottled yellow (Sample SM11), light yellow (Samples S2, S7), grey (Sample HM1), dark brown (Sample B12) and very dark brown (MT54) grog. Quartz is always present, although the modal size and distribution varies significantly between samples with fine a-r quartzes (Samples SM11), whilst larger sr-r inclusions also occur (Sample B12). Basic igneous inclusions of dolerite occur (Samples B12, E3, HM1, MT2), which vary between un-weathered (Sample B12) and highly weathered inclusions (Sample E3). Optical activity varies with high optical activity (Samples SM11, S2), mild activity (Sample MT2), low activity (Sample B12, HM1, MT52), and optically inactive (Sample E3). Optical density varies from sample to sample, with low optical density (Samples B12, S7), high optical density (Samples MT2, E5), low and high optical density (Samples E4, HM1) and neutral to almost neutral optical density (Samples E3, E10). Ring voids are present in all samples. 
predominant-rare: Dolerite; el \& eq. sa-r. $<5.60 \mathrm{~mm}$. Mode $2.00 \mathrm{~mm}$. Inclusions can be olivine rich (Samples B12, HM1) or containing only olivine, pyroxene and feldspar (Samples S4, E5), or pyroxene and feldspar only (Sample MT2). Size of constituent crystals varies greatly within and between samples, with a grain size consistent with basalt occurring in one sherd (Sample HM1). Feldspars are mostly equigranular, with one exception (Sample SM11), being lath shaped, simply twinned and randomly orientated. Flow is visible in one inclusion only (Sample MT54). Sub-ophitic texture occurs in several sherds (Samples E3, E5, MT2). Olivine crystals are almost exclusively subhedral, varying in condition with some weathering occurring in all samples, especially in the larger crystals. Iron rich basic igneous occurs in one sample (E10). One very weathered inclusion (Sample SM11) is at an advanced stage of weathering with only the feldspars being distinguishable. This fragment contains a small amount of precipated silicate mineral similar to chert, possibly filling a vesicle in an amygdaloidal texture.

dominant-few: Quartz; el \& eq. sa-r. $<0.88 \mathrm{~mm}$. Mode $0.24 \mathrm{~mm}$. Straight or undulose extinction.

few-absent: Polycrystalline quartz; $<0.56 \mathrm{~mm}$. el \& eq. sr. Mode $0.32 \mathrm{~mm}$. Straight and undulose extinction.

few-absent: $T F$ 's; el \& eq. sa-r. $<0.48 \mathrm{~mm}$. Mode $0.32 \mathrm{~mm}$. Opaque, dark brown and brown in colour. Sharp to merging boundaries. Discordant. Optically inactive (Sample E5) to active (Sample E4). Inclusions occurring in fine and coarse fraction, relating to weathering of the clay to TF. Can contain streaks (Sample HM1).

very rare-absent: Argillaceous inclusions; eq. sr. $<2.00 \mathrm{~mm}$. Consists of brown inclusion containing sr-r quartzes and white mica (Sample S1).

very rare: Sandstone; el \& eq. sa-sr. $<0.64 \mathrm{~mm}$. May be sub-arkrosic or quartz arenite (Sample MT54).

very rare: Feldspar; eq. sa. $<0.72 \mathrm{~mm}$. (Samples E10, S7).

very rare: Chert; el, a, <0.56mm.

$\underline{\text { Fine fraction }}$

20-60\%. 0.24-0.01mm.

predominant: Quartz

few-rare: White mica

very rare-absent: Feldspar

very rare-absent: Polycrystalline quartz

very rare-absent: Acid igneous 
very rare-absent: Chert

very rare-absent: Shale

$\underline{\text { Matrix }}$

50-80\%. Non-calcareous. In PPL (x40) colour ranges from light yellow brown, to red brown to dark brown. In XP colour varies from light yellow brown to very dark brown. Core margin colour differentiation occurs in many sherds (Samples E4, HM1, S7). Optical activity ranges from optically inactive (Sample S7), to moderate optical activity (Samples B12, MT24), to a high level of optical activity (Samples MT2, S2).

$\underline{\text { Voids }}$

5-15\%. Consists of micro-channels (Sample HM1), channels (Samples MT2, E3), mega channels (Sample E10), vesicles (Sample E4), mega vesicles (Sample E5), vughs (Samples E3, S2), and mega vughs (Sample B12, HM1). Poor to (Samples E3, HM1) strong alignment (Samples E4, S7), of which the latter may relate to relic coil structures. Blackening around the edges (Sample E10) may relate to charred naturally occurring organics.

\section{Comments}

This fabric is defined by the presence of both grog and dolerite temper being added to a non-calcareous clay, although there is clear variation between individual sherds that suggest separate provinces for most samples. Firstly the colour of the grog and the shape and type of inclusion varies with many of the examples. Secondly, there is wide variation between the abundance and modal size of the quartz inclusions in this fabric. The amount of quartz in the coarse and fine fraction varies greatly between sherds, with Sample E3 filled with naturally occurring quartz, whilst E10 contains relatively few. The modal grain size also varies from sample to sample, with MT54 containing individual grains which are larger in comparison to the other sherds in this fabric.

The presence of grog with varying optical densities suggests two possibilities. In Samples such as E4 the cause would appear to be due to both oxidation and reduction occurring within pot during firing. However with Samples MT54 and HM1 the colour and textural variations suggests that grog from more than one pot was being added to the clay matrix, with two vessels represented in MT54, whilst HM1 appears to contain grog from three separate vessels.

The dolerite and basalt temper in this fabric is comparable in texture and modal grain size to the distribution of such inclusions in Fabric 1. This indicates that complimentary resources were being used, all being available within the general geology of the Peak District. Relic coils are represented by the alignment of voids in Samples E4 and S7. The colour variation and optical activity within all sherds suggests a poorly controlled firing in an oxidising atmosphere, at a relatively low temperature. The only exception to this is Sample S7, a ceramic that has undergone a reduced firing with slight oxidation of the edges. The presence of dolerite temper contained within the grog inclusions of Samples B12, E3, HM1, and MT2 suggests a tradition of re-using dolerite tempered pots in the fabrication of new vessels. It can therefore be concluded that the clay and temper for each individual sample originated from a different source, and that the sherds 
are therefore grouped only in the similarity of their recipes, not a commonality of raw materials.

\section{FABRIC 4 - POLYCRYSTALLINE QUARTZ TEMPER IN NON-CALCA- REOUS CLAY}

\section{$\underline{\text { Samples }}$}

B8, B11, B15)

$\underline{\text { Inclusions }}$

$15-25 \%$, eq \& el. Single - open spaced. Crude alignment to margins of samples. Highly bimodal grain size distribution.

\section{$\underline{\text { Coarse Fraction }}$}

$50-60 \%, 2.56-0.16 \mathrm{~mm}$.

predominant: Polycrystalline quartz; eq \& el, r-a. $<2.56 \mathrm{~mm}$. Mode $=0.88 \mathrm{~mm}$. Polycrystalline quartz fragments generally demonstrate undulose extinction, whilst a few crystals in B11 showing severe alteration which appears almost metamorphosed in character. Samples are generally coarse to medium grained.

common: Quartz; eq \& el, r-a. $<1.28 \mathrm{~mm}$. Mode $=0.32 \mathrm{~mm}$. Straight or undulose extinction.

common-very few; $T F$ 's; el \& eq. sr-r. $<0.88 \mathrm{~mm}$. Mode $0.32 \mathrm{~mm}$. Dark brown to brown to red in colour. Sharp to merging boundaries. Composed of argillaceous inclusions and clay pellets (Sample B8). High optical density.

rare: Nepheline; eq \& el, sa-a. $<1.12 \mathrm{~mm}$. Mode $=0.60 \mathrm{~mm}$. (B11) Inclusions demonstrate well developed crystal faces with characteristic hexagonal structure seen in one inclusion.

rare: Quartz arenite; eq, sa-r. $<1.44 \mathrm{~mm}$. Mean $0.88 \mathrm{~mm}$.

very rare-absent; Chert: (B11). el, sr. <0.80mm.

very rare-absent: Altered acid igneous rock fragment (B11). el, sa. Size 0.80mm. Probably a weathered granite.

very rare-absent: Shale; el. sr. $<0.80 \mathrm{~mm}$ (Sample B8).

$\underline{\text { Fine Fraction }}$

$40-50 \% .0 .16-0.01 \mathrm{~mm}$

predominant: Quartz 
rare - very rare: White mica

$\underline{\text { Matrix }}$

65-75\%. Non-calcareous. Very dark brown to light brown in PPL. Dark brown to light orange brown in XP (x40). Core margin colour variation. Moderate to high optical activity.

$\underline{\text { Voids }}$

5-8\%. Consists of mega-channels, vesicles and vughs. Poor to strong alignment in many of the vesicles, related to relic coil structures.

\section{Comments}

This fabric is limited to three samples, characterised by the addition of polycrystalline quartz temper to non-calcareous clay, dominated by naturally occurring mono-crystalline quartz in the fine fraction. There is some variation within the two sherds, with the presence of almost metamorphosed poly-crystalline quartz fragments in B11 which are not found in B15. As with the presence of other minor inclusions such as chert (B11) may be due to natural variation in the parent clay. The sub-angular nature of the polycrystalline quartz temper would appear to preclude a fluvial origin, making a source of glacial provenance more likely. The presence of nepheline in sample B11 is unusual as it has only been observed in a few samples from other fabrics. As this rock forming mineral does not occur naturally with quartz, a different source for the clay may be indicated. Striations within the clay matrix of Sample B11 indicate relic coils. The colour variation and optical activity within the two sherds suggests a poorly controlled firing in an oxidising atmosphere.

\section{FABRIC 5 - GROG TEMPER IN NON-CALCAREOUS CLAY}

\section{$\underline{\text { Samples }}$}

DD1, HM1, GH1, OA1, RL1, SM5, WL1.

\section{$\underline{\text { Inclusions }}$}

15-30\%. el \& eq. Open spaced, single space and less. Strong (Sample SM5) to crude alignment (Samples GH1, OA1, RL1, WL1) to margin of samples. Highly (Samples DD1, GH1, RL1, SM5, WL1) to weakly bimodal (Sample OA1) grain size distribution.

\section{$\underline{\text { Coarse Fraction }}$}

\section{$50-90 \%$. 3.44-0.24mm}

predominant-dominant: Grog; eq \& el. sa - sr. $<3.44 \mathrm{~mm}$. Mode $2.4 \mathrm{~mm}$. Composed of dark to light brown (Sample SM5), straw yellow to red brown to dark brown (Sample WL1), and light yellow brown grog (Sample GH1),containing inclusions of quartz in all samples, angular chert (SM5), and second generation grog (Sample WL1). Modal 
size and distribution of the quartz inclusions within the grog temper varies significantly between samples, with abundant fine grains (Sample GH1) to larger but fewer grains (Sample RL1). Optical activity varies between optically active (Sample GH1) to poor optical activity (Sample SM5). Second generation grog is also seen in one inclusion (Sample WL1). Optical density varies between samples, with high optical density (Samples SM5, RL1), low optical density (Samples GH1) and both low and high optical density (Samples OA1, WL1), Shrinkage voids occur in all samples.

frequent-few: Quartz; eq \& el. sa-r. $<0.88 \mathrm{~mm}$. Mode $=0.32 \mathrm{~mm}$. Straight or undulose extinction.

few-absent: $T F$ 's: eq \& el. sa-wr. $<0.48 \mathrm{~mm}$. Light yellow brown (Sample RL1) to dark red brown and dark brown (Samples WL1 and GH1). High to neutral optical activity. Sharp to merging boundaries. Inclusions occuring in fine and coarse fraction, relating to weathering of the clay to TF. Streaks and swirls also occur (Samples RL1 and SM5).

very rare-absent: Polycrystalline Quartz; $<1.04 \mathrm{~mm}$. Mode $=0.48 \mathrm{~mm}$. Consists of fine grained quartz fragments demonstrating undulose extinction (Samples GH1, SM5, WL1). One inclusion (Sample GH1) appears metamorphosed. One inclusion (Sample GH1) appears to originate from a sandstone fragment.

very rare-absent: Chert; eq \& el. sa-r. (Samples OA1 and WL1).

very rare-absent: Basalt; eq. sr. 0.96mm. (Sample RL1). Inclusion poorly preserved in section.

very rare-absent: Weathered Acid Igneous; <2.0mm. el. a. Granite. (Samples DD1 and GH1).

very rare-absent: Microcline; $1.28 \mathrm{~mm}$. el. a. (Sample HM1).

very rare-absent: Argillaceous Inclusion; $2.00 \mathrm{~mm}$. el. sr. Contains sub-rounded monocrystalline quartz fragments. (Sample DD1).

$\underline{\text { Fine fraction }}$

$10-50 \% .0 .24-0.01 \mathrm{~mm}$.

predominant-dominant: Quartz

few-very rare : White mica

very rare-absent : Phyllite

very rare-absent: Feldspar

very rare-absent: Polycrystalline quartz

$\underline{\text { Matrix }}$ 
65-80\%. Non-calcareous. Light brown to very dark brown in PPL, straw yellow to red brown to dark brown in XP (x40). Heterogeneous (Sample RL1) to homogeneous (Sample SM5). Core margin colour variation (Samples DD1, GH1, OA1, WL1). Striations within the clay matrix of SM5 may indicate relic coils.

$\underline{\text { Voids }}$

2-15\%. Consists of channels and vesicles (Sample GH1), vesicles (Sample OA1), mega vughs and vesicles (Sample SM5), mega vesicles (Sample RL1), and channels and mega-vughs (Sample WL1). Angular voids are found in HM1.

\section{$\underline{\text { Comments }}$}

This fabric is defined by the presence of grog temper in non-calcareous clay, although there is clear variation between individual sherds that suggest separate provinces for each sample. Firstly the colour of the grog and the shape and type of inclusion varies from sample to sample, for example chert temper is evident SM5, whilst in WL1 second generation grog was utilised. Secondly, there is a wide variety between the abundance and modal size of the quartz inclusions in this fabric, most notable between Samples WL1 and RL1, which contain only a limited number throughout their matrices, and a general lack of inclusions in the fine fraction. In comparison, Sample GH1 contains an abundance of smaller quartzes evenly distributed throughout the matrix. The high and low optical activity with Sample WL1 is suggestive of grog originating from two separate vessels.

The colour variation and optical activity within all sherds indicates a poorly controlled firing in an oxidising atmosphere, with the exception of GH1 which is reduced apart from an oxidised outer edge. It can therefore be concluded that the clay and temper for each individual sample originated from a different source, and that the sherds are therefore grouped only in the similarity of their recipes, not a commonality of raw materials.

\section{FABRIC 6 - SANDSTONE TEMPER IN NON-CALCAREOUS CLAY}

\section{$\underline{\text { Samples }}$}

MT11, MT22, MT27, MT28, MT32.

\section{$\underline{\text { Inclusions }}$}

20-35\%. el \& eq. Open spaced, single spaced or less. Strong (Sample MT28) to crude (MT32) alignment to margin of samples. Highly bimodal grain size distribution.

\section{Coarse Fraction}

\section{$70-90 \% .8 .8-0.24 \mathrm{~mm}$.}

predominant-frequent: Sub-arkrose; el \& eq. sa-sr. $<8.8 \mathrm{~mm}$. Mode $2.8 \mathrm{~mm}$. Consists of a range of poorly sorted, coarse to medium grained quartz rich rock fragments. 
dominant-common: Quartz; el \& eq. Sa-r. $<0.72 \mathrm{~mm}$. Mode $0.32 \mathrm{~mm}$. Straight or undulose extinction. Larger quartzes may relate to sandstone fragments.

dominant-common: Argillaceous inclusions; el \& eq. sr. A range of light brown (MT28) to dark brown (MT32) argillaceous inclusions containing sa-sr quartz, the latter two identified as shale. One inclusion is arf shaped (MT27).

very rare: Feldspars; eq. sr. $<0.80 \mathrm{~mm}$. Mode $0.32 \mathrm{~mm}$.

very rare-absent: Phyllite. el. sr. <0.40mm (Sample MT26).

very rare-absent: Basic igneous. eq. r. $<0.56 \mathrm{~mm}$. Very weathered fragment (Sample MT27). Grain size suggests basalt.

common-few: Polycrystalline quartz; el \& eq. sr. $<1.36 \mathrm{~mm}$. Mode $0.40 \mathrm{~mm}$. Undulose extinction. May relate to sub-arkrose.

rare: $T F^{\text {s. }}$ : el \& eq. sr-wr. $<1.76 \mathrm{~mm}$. Mode $0.40 \mathrm{~mm}$. Low (Sample MT22) to almost neutral (Sample MT27) optical activity. Sharp to merging boundaries. Discordant. Comprised of optically inactive dark brown clay containing sa-sr quartz inclusions (Sample MT27). Weathered brown (MT28) to very dark brown (MT27). Clay pellets and streaks (MT27).

very rare-absent: Micrite; el. sr. <0.56mm (Sample MT32).

very rare-absent: Chert; el. sr. $<2.64 \mathrm{~mm}$. (Sample MT32). Inclusion is iron rich with siliceous microfossils converted to fine quartz. Chert shows layering and chalcedonic properties.

\section{$\underline{\text { Fine Fraction }}$}

predominant: Quartz

few-rare: White mica

few-rare: Feldspar

few-rare: Polycrystalline quartz

very rare-absent: Chert

very rare-absent: Phyllite

\section{$\underline{\text { Matrix }}$}

55-70\%. Non-calcareous. Light brown to very dark brown in PPL. Yellow brown to very dark brown in XP (x40). Core margin colour differentiation (Sample MT32). Heterogeneous related to core margin colour differentiation. Optically inactive (MT32) to optically active (Sample MT27) 
5-10\%. Consisting of mega-vughs (Samples MT28, MT32), channels, vesicles and mega-vesicles (Samples MT27). No (Samples MT26) to crude alignment (Samples MT32) to margin of samples.

\section{$\underline{\text { Comments }}$}

This fabric is characterised by the addition of large inclusions of coarse sandstone to non-calcareous clay containing a variety of naturally occurring inclusions. The fabric is generally homogeneous, especially as regards Samples MT26, MT28 and MT32, although Sample MT 27 has a finer clay matrix and is completely oxidised. The samples appear to have been fired at a low temperature in a poorly controlled atmosphere with almost complete reduction occurring (Sample MT32) and almost complete oxidation occurring in other sherds (Sample MT27). The presence of argillaceous material in addition to smaller amounts of phyllite, micrite, basic igneous, etc, suggest a clay source close to the boundary of the White Peak and Gritstone Uplands, therefore containing small amounts of rocks which occur naturally in both zones. The coarse sub-arkrose temper occurs extensively over the Gritstone Uplands.

\section{FABRIC 6A - SANDSTONE TEMPERED SUB-FABRIC}

\section{$\underline{\text { Samples }}$}

S4.

This sample differs from the main fabric on several criteria. Firstly, the sandstone temper is less coarse, being consistent with sub-rounded and fine grained quartz arenite. Inclusions within the clay matrices also separate this sherd, for instance sub-rounded to rounded quartzes. Textural features differ in that they occur as optically inactive streaks and clay pellets. The fine fraction contains less variety of inclusions. As this fragment is also from a different site to the main fabric, a different source for both clay and temper is indicated.

\section{FABRIC 7 - WEATHERED ACID IGNEOUS ROCK IN NON-CALCAREOUS CLAY}

$\underline{\text { Samples }}$

B2, MT1, MT12, MT18, MT43, MT51.

$\underline{\text { Inclusions }}$

20-45\%. eq and el. Single - open spaced. No alignment (B2, MT12, MT18), to crude (MT1, MT51), to strong (MT43) alignment to margin of samples. Bimodal to strongly bimodal grain size distribution.

\section{Coarse Fraction}


$30-60 \%, 7.76-0.08 \mathrm{~mm}$

predominant - rare: Weathered Igneous rock; el \& eq. sa-sr. Maximum grain size, $7.76 \mathrm{~mm}$. Mode $1.28 \mathrm{~mm}$. Inclusions are variable within and between samples. Iron rich examples similar to chert occur in MT43, but differ on account of mineral banding and ghost phenocrysts within the rocks, each with high interference colours. One inclusions in MT43 appear to be a highly weathered basalt. Another inclusion within the same sherd is silica rich, containing weathered crystals of sanadine. In B2 and MT1, silica rich rocks similar to chert have brown edges. Only in B2 and MT12 do un-weathered inclusions occur, being indicative of rhyolite. With the exception of the single basalt inclusion, the majority appear to be basic or intermediate in origin.

dominant - frequent: Quartz; el \& eq. a - wr. $<0.80 \mathrm{~mm}$. Mode $0.32 \mathrm{~mm}$. Undulose extinction. Can be monocrystalline or polycrystalline.

common - absent: Shale; el. sr. Maximum grain size $<1.6 \mathrm{~mm}$. Mode $0.80 \mathrm{~mm}$. found only in MT51.

rare - absent: Chert; el \& eq. a - wr. <1.20mm. Mode $0.64 \mathrm{~mm}$. A mixture of weathered and un-weathered examples occur in MT1, MT12, MT18, and MT43. Some examples are iron rich (MT1 and MT43).

rare - absent: Sandstone; eq. sr-r. $<2.08 \mathrm{~mm}$. Mode $0.72 \mathrm{~mm}$. Consists of quartz rich rock fragments of sub-arkrose (B2, MT1, MT12). The inclusion in MT1 is notably finer grained.

very rare - absent: Siltstone; eq. r. 1.84mm (MT18)

very rare - absent: Basic Igneous; el. sr. $0.80 \mathrm{~mm}$. A single inclusion occurs in MT12, which is weathered, with only the feldspars being visible, demonstrating no flow. Grain size is consistent with dolerite.

very rare - absent: Feldspar; el. sr. 0.32mm. Contains cross-hatched twinning (MT12).

\section{$\underline{\text { Fine Fraction }}$}

predominant: Quartz

common - very rare: Phyllite

very rare - absent: White Mica

very rare - absent: Chert (MT12)

very rare - absent: Feldspar (MT51)

very rare - absent: Acid Igneous rock (B12)

\section{$\underline{\text { Matrix }}$}


35-50\%. Non-calcareous. Ranging from light brown to very dark brown in most samples in PPL, with the exception of MT43, which is entirely very dark brown. Light brown to very dark brown in XP (x40), with the exception of MT43 which is black.

Core margin variation is seen in B12, MT12, MT1, MT18, and MT51, consisting of a reduced centre and oxidised outer edge. Complete reduction is only evidenced in MT43. Heterogeneous related to core margin colour differentiation, with MT43 being homogeneous. Optical activity ranges from inactive (MT43), to slightly active (MT1, MT12), to active (B2, MT1). The evidence suggests a poorly controlled firing for this fabric which caused both partial and complete reduction, with some being below $850^{\circ}$

\section{$\underline{\text { Voids }}$}

5-20\%. Consisting of channels (B2), mega-channels (MT12), vesicles (B2, MT43), mega-vesicles (MT18, MT43), and mega-vughs in all samples. No alignment (MT18, MT43), to crude alignment (B2), to strong alignment (MT12) indicates a coil built vessel.

\section{Comments}

This fabric is characterised by a very densely packed matrix dominated by weathered igneous rocks and quartzes, with five samples originating from the site of Mam Tor. The high amount of quartz and homogeneity within coarse and fine fractions suggests a single weathered clay source was utilised on or near the Gritstone Uplands. This is supported by the common inclusions in the coarse and fine fractions, for instance chert, basic igneous, and sandstone. The additional presence of variable and weathered igneous inclusions may be indicative of a boulder clay source. Although their bimodal distribution suggests intentional tempering, the character of the matrices may suggest naturally weathered components.

The two sub-fabrics are similar in composition to the main fabric, but display enough variation to suggest that they have been constructed from different raw material sources. This is especially apparent regarding the clay matrices, which are clearly unrelated.

\section{WEATHERED IGNEOUS AND QUARTZ SUB-FABRIC 7A}

\section{$\underline{\text { Samples }}$}

\section{S3.}

This sample differs from the main fabric in both clay and acid igneous inclusions, whilst containing enough similarities to classify it as a sub-fabric. The clay matrix is relatively clean, containing only sparse inclusions of sub-rounded to rounded quartz. The coarse fraction contains a lot more inclusions of shale, which demonstrate crude alignment to the margin of samples. In comparison, the acid igneous inclusions are similar to the main fabric. Several inclusions are opaque and iron rich, being similar in appearance to chert. There are also crystals with high interference colours and epidote. Other mineral 
crystals within the inclusions are difficult to identify but may be amphibole or biotite. There are no remains of phenocrysts. These inclusions may be altered intermediate or acid igneous rocks. Core margin colour differentiation and high optical activity are displayed.

\section{WEATHERED IGNEOUS SUB-FABRIC 7B}

$\underline{\text { Samples }}$

SM6.

This sample differs from the main fabric due to the lack of quartz in the coarse and fine fraction, and the better preservation of the sub-rounded igneous inclusions. Two inclusion are similar to chert yet contains phenocrysts, with one being iron rich. Another example appears to be a fusion of iron rich silicate and plagioclase feldspars. These may represent some form of igneous rock. The other main inclusion consists of clay pellets, with a distribution that indicates a relic coil. Core margin colour variation and high optical activity is also evident.

\section{FABRIC 8 - ROUNDED QUARTZ FABRIC IN NON-CALCAREOUS CLAY}

\section{$\underline{\text { Samples }}$}

RG1, RG9.

\section{$\underline{\text { Inclusions }}$}

20\%. el \& eq. sa-wr Open spaced. Crude (RG9) to strong alignment (RG2) to margin of samples. Weakly bimodal grain size distribution.

\section{$\underline{\text { Coarse fraction }}$}

$55 \% .1 .36-0.24 \mathrm{~mm}$.

predominant: Quartz; eq \& el. sa-r. $<0.88 \mathrm{~mm}$. Mode $0.32 \mathrm{~mm}$. Straight and undulose extinction.

very rare: Acid igneous; eq. sr. $<1.6 \mathrm{~mm}$. Weathered inclusion. Probably granite (RG9). In RG1, inclusion is silica rich with high interference colours in places. Possibly a volcanic rock.

very rare: Chert: el. sr. $<0.40 \mathrm{~mm}$. Inclusion is iron rich.

very rare: Feldspar; el. sr. $<0.56 \mathrm{~mm}$. Simply twinned.

very few - very rare: Polycrystalline quartz. el \& eq. sr-r. $<0.80 \mathrm{~mm}$. Straight and undulose extinction. 
very rare - absent: Basic igneous: eq. r. 0.48mm. Contains simply twinned feldspars and olivine. Grain size consistant with dolerite (RG1).

very rare - absent: Sandstone: eq. Sr. 0.88mm.Qartz rich fragment,consistant with a sub-arkrose (RG1).

rare-absent: Sandstone; el \& eq. sa-r. $<0.88 \mathrm{~mm}$. A range of quartz rich fragments, ranging from quartz arenite (Samples G3, MT30), sub-arkrose (Samples G8, G43), and quartzwacke (Sample MT30, MT31).

rare - absent: $T F^{\text {s }}$; el \& eq. sr-r. $<1.60 \mathrm{~mm}$. Mode $0.40 \mathrm{~mm}$. High optical density (B2, MT1, MT18). Sharp boundaries. Discordant. Composed of optically inactive dark brown streaks (MT18), and clay pellets. Possibly the result of weathering of the clays to TF's.

$\underline{\text { Fine fraction }}$

$45 \% .0 .24-0.01 \mathrm{~mm}$.

dominant: Quartz

rare: Polycrystalline quartz

rare: Feldspars

very rare: White mica

very rare: Chert

$\underline{\text { Matrix }}$

45\%. Non-calcareous. Black in PPL. Very dark brown to dark brown in XP (x40). Homogeneous. No core/margin colour differentiation in RG9, but core margin colour variation in RG1. Optically inactive.(RG9) to active at the margins (RG1).

$\underline{\text { Voids }}$

45-10\%. Consisting of mega vughs, channels and vesicles.

\section{Comments}

These two sherds both originate from Roystone Grange (Site 23), and are characterised by the addition of quartz temper to non-calcareous clay with the rounded nature of many of the inclusions suggesting a fluvial source. The presence of weathered chert, acid igneous and basic igneous could be indicative of a glacial clay source. Similarities are seen with other samples from this site represented in Fabric 1D especially RG2 and RG5. They all contain relatively large and rounded quartz inclusions in the clay matrix, in addition to a generally reduced nature. They may possibly be related samples but this is not certain. 
Both samples were fired in a generally reducing atmosphere, with firing temperature difficult to estimate in RG9. The most notable feature of RG9 is the presence of such a high percentage of voids, crudely aligned to the margins of the sample. This alignment could be the result of organic temper burnt out during firing, with the blackened margins hidden by the reducing atmosphere within which the ceramic was fired. Alternatively the clay may have been poorly processed, leaving a large amount of voids within the matrix. Clear indications of coil building are seen in the distribution of quartz inclusions in RG1.

\section{FABRIC 9 - ACID IGNEOUS IN NON-CALCAROUS CLAY}

\section{$\underline{\text { Samples }}$}

G38.

\section{$\underline{\text { Inclusions }}$}

20\%. el \& eq, sa-sr, single to open spaced. Crude alignment to margin of samples. Bimodal grain size distribution.

\section{Coarse Fraction}

$35 \% .2 .64-0.24 \mathrm{~mm}$.

dominant: Weathered acid igneous; eq, sr. $<2.56 \mathrm{~mm}$. Containing feldspar, mica and quartz, probably granite. Zoning of feldspar crystal in one inclusion.

common: Quartz; el \& eq, sa-wr. <1.28mm. Mode 0.40mm. Undulose extinction.

very rare: Biotite mica; el, a. $<1.28 \mathrm{~mm}$. Inclusion demonstrates perfect cleavage characteristic of mineral.

very rare: Argillaceous inclusion. el, sr. $<2.56 \mathrm{~mm}$. Dark brown inclusion with low optical density. Sharp boundary. Probably shale.

very rare: Chert; eq, sr. $<0.88 \mathrm{~mm}$.

very rare: $T F$ 's; eq. sr. $<0.40 \mathrm{~mm}$. Dark brown in colour. Low optical density. Sharp boundaries. Composed of clay inclusions containing quartz and mica, possibly clay pellets. Also streaks.

\section{Fine Fraction}

$65 \%, 0.24-0.01 \mathrm{~mm}$

predominant: Quartz

very rare: White mica 
very rare: Plagioclase Feldspar

very rare: iron rich minerals

\section{$\underline{\text { Matrix }}$}

$70 \%$. Non-calcareous. Light brown to brown to very dark brown in PPL. Light yellow brown to very dark brown in XP (x40). Heterogeneous related to core margin differentiation. Moderately optically active to optically inactive.

\section{$\underline{\text { Voids }}$}

$10 \%$. Consists of micro and mega vughs, channels and vesicles. Poor alignment to margin of section. Blackened margin of one channel possibly relating to charred organic inclusion.

\section{Comments}

This sherd is characterised by the presence of weathered acid igneous inclusions, probably granite, and small amounts of other naturally occurring inclusions, such as chert, biotite mica and shale. Although the acid igneous inclusions are considerably larger in size the small number within the section would suggest a glacial source for the clay and inclusions, rather than being purposely added as temper. The sample appears to have been fired in a generally reducing atmosphere which was difficult to control, although firing temperature is difficult to estimate due to the lack of optical activity in such a dark matrix. No signs of coils or wheel finishing were noted.

\section{FABRIC 10 - SANDSTONE TEMPER IN NON-CALCAREOUS CLAY}

\section{Samples:}

SH1.

\section{$\underline{\text { Inclusions }}$}

$30 \%$. el \& eq. sa-r. Single spaced or less. Crude alignment to margin of samples. Highly bimodal grain size distribution.

\section{$\underline{\text { Coarse fraction }}$}

$70 \% .3 .84-.024 \mathrm{~mm}$

predominant: Coarse grained sandstone: eq, sr. $<3.84 \mathrm{~mm}$. Mode $1.6 \mathrm{~mm}$. Composed of sa-sr monocrystalline quartz fragments (Straight and undulose extinction) and feldspars. Moderately to poorly sorted grain size distribution. Could be classed as quartz arenite.

common: Quartz: el \& eq. sr-r. <2.0mm. Mode $0.4 \mathrm{~mm}$. Straight and undulose extinction. Probably originated from the coarse sandstone. 
common: $T F$ 's: eq \& el. sr-wr. $<0.72 \mathrm{~mm}$. High optical density. Sharp boundaries. Discordant. Occur in the coarse and fine fraction. Related to weathering of the clay.

very few: Fine grained, altered sandstone: eq \& el, sr. $<0.88 \mathrm{~mm}$.

very rare: Feldspar (microcline): eq, sr. $0.56 \mathrm{~mm}$.

very rare: Chert. eq, sr. $0.56 \mathrm{~mm}$.

very rare: Phyllite: el, a. $0.48 \mathrm{~mm}$.

very rare: Argillaceous inclusion: eq, sr. $<2.0 \mathrm{~mm}$. Consists of light brown to red brown inclusions containing sa-sr quartz. Low optical density. Sharp to merging boundaries.

\section{$\underline{\text { Fine Fraction }}$}

$30 \% .0 .24-0.01 \mathrm{~mm}$.

dominant: Quartz

very few: Feldspar

very rare: White Mica

\section{$\underline{\text { Matrix }}$}

40\%. Non-calcareous. Light yellow brown to very dark brown in PPL. Light orange brown to dark brown in XP (x40). Heterogeneous. Core margin colour differentiation. Optically active.

\section{$\underline{\text { Voids }}$}

$30 \%$. Mainly mega-vughs and channels. Poor alignment to margin of sections.

\section{$\underline{\text { Comments }}$}

This sherd is characterised by the presence of large inclusions of coarse sandstone temper, with a variety of smaller, naturally occurring inclusions within the matrix, such as sandstone, chert and phyllite. This variety would suggest that the clay was obtained from a boulder clay source near the border of the White Peak and Gritstone Uplands, whilst the temper could have been obtained anywhere within the latter. The sample appears to have been fired in an oxidising atmosphere at a relatively low temperature. No signs of coils or wheel finishing were noted.

\section{FABRIC 11 - CHERT AND GROG TEMPER IN NON-CALCAREOUS CLAY}

\section{$\underline{\text { Samples }}$}


SM3.

$\underline{\text { Inclusions }}$

20\%. el \& eq. a -sr. Open spaced. Crude alignments to margin of samples. Bimodal grain size distribution.

\section{$\underline{\text { Coarse fraction }}$}

$90 \% .5 .0-0.16 \mathrm{~mm}$.

predominant : Chert; eq \& el. a - sr. $<5.0 \mathrm{~mm}$. Mode $0.40 \mathrm{~mm}$. Larger chert inclusions show macro-quartz which appear to contain inclusions of carbonate, suggesting a limestone source.

common: Grog; eq \& el. sr-wr. <3.2mm. Mode $1.2 \mathrm{~mm}$. Light orange brown to dark brown. Optically active. Sharp to merging boundaries. Can contain sa-sr quartz and chert. Can have shrinkage voids.

few: Iron rich opaque inclusions; eq. sr. $<0.72 \mathrm{~mm}$. Possibly related to TF's.

rare: Quartz. eq \& el. a-sr. $<0.56 \mathrm{~mm}$. Mode $0.24 \mathrm{~mm}$.

very rare: Acid igneous. eq. sr. Probably weathered granite.

Fine fraction

$10 \% .0 .16-0.01 \mathrm{~mm}$

dominant: Quartz

common: Chert

very rare: feldspar

$\underline{\text { Matrix }}$

45\%. Non-calcareous. Very dark brown to light red brown in PPL. Very dark brown to light orange brown in XP (x40). Heterogeneous. Related to TF's. Core margin colour differentiation. Optically very active in oxidised areas.

\section{$\underline{\text { Voids }}$}

$30 \%$. Consisting of vesicles, vughs and mega channels. Strong alignment to margin of sample. Possibly indicates relic coil structure.

\section{Comments}

This sherd is characterised by the presence of chert temper, which demonstrates characteristics that would suggest a marine origin and therefore procurement somewhere on 
the White Peak. The non-calcareous clay does not contain any of the usual components seen in clays from the Gritstone Uplands, for instance shale or sandstone. Therefore the clay may also have been obtained from elsewhere. The sample appears to have been fired at a relatively low temperature in a mostly reducing but poorly controlled atmosphere, where the outer edges of the sherd were oxidised. Possible coil construction is indicated by the orientation of the voids.

\section{FABRIC 12 - CALCITE, CHERT, AND FINE GRAINED QUARTZ IN NON- CALCAREOUS CLAY}

$\underline{\text { Samples }}$

MD1.

\section{$\underline{\text { Inclusions }}$}

$15 \%$. el \& eq. sr. Open spaced. Crude alignment to margin of samples. Highly bimodal grain size distribution.

\section{Coarse fraction}

$60 \% .2 .00-0.32 \mathrm{~mm}$.

frequent: Calcite. el \& eq. sa-sr. $<1.28 \mathrm{~mm}$. Mode $1.20 \mathrm{~mm}$. Calcite is fine grained with no sign of microfossils; can be classified as micrite.

common: Quartz; el \& eq. sa-sr. $<0.72 \mathrm{~mm}$. Mode $0.40 \mathrm{~mm}$. Straight and undulose extinction.

common: Polycrystalline quartz: el \& eq. sa-sr. $<1.28 \mathrm{~mm}$. Mode $0.64 \mathrm{~mm}$. Straight and undulose extinction.

few: Chert: el \& eq. sr. $<1.68 \mathrm{~mm}$. Sample shows radial fibrous structure diagnostic of chalcedonic quartz.

rare: $T F$ 's: el \& eq. sr-wr. $<0.64 \mathrm{~mm}$. Mode $0.48 \mathrm{~mm}$. Red Brown to Brown. Low to neutral optical density. Sharp to merging boundaries. Composed of optically inactive/brown clay inclusions, some contained sr quartz. Occur in coarse and fine fraction. Result of weathering of clay to TF.

very rare: Quartz arenite; eq. sr. $<1.6 \mathrm{~mm}$. Consists of fine grained quartz rich rock fragment.

$\underline{\text { Fine fraction }}$

predominant: Quartz

rare: White mica 
very rare: Feldspars

very rare: Chert

$\underline{\text { Matrix }}$

70\%. Non-calcareous. Brown to dark brown in PPL. Red brown to dark brown in XP (x40). Moderately heterogeneous. Core margin colour differentiation. Optically active.

$\underline{\text { Voids }}$

$15 \%$. Consist of channels, vesicles, mega channels and mega vughs.

\section{Comments}

This sherd is characterised by the presence of calcite and chert in non-calcareous clay, with the weathered state of these inclusions suggesting that they may occur naturally within the clay matrix. The highly bimodal grain size distribution contradicts this, indicating that they were added as temper. The presence of such inclusions would suggest that the raw materials were sourced somewhere on the White Peak. Sample has been relatively low fired in a poorly controlled atmosphere. No signs of relic coils or other forms of finishing.

\section{FABRIC 13 - QUARTZ AND BONE IN NON-CALCAREOUS CLAY}

\section{$\underline{\text { Sample }}$}

IM1.

\section{Inclusions}

$20 \%$ el \& eq. sa-sr. Open spaced. No alignment to margin of sample. Weakly bimodal grain size distribution.

\section{$\underline{\text { Coarse fraction }}$}

$50 \% .1 .12-0.16 \mathrm{~mm}$.

dominant: Quartz; el \& eq. sa-sr. $<0.40 \mathrm{~mm}$. Mode $0.24 \mathrm{~mm}$. Undulose extinction.

frequent: Bone; el. sr. $<0.80 \mathrm{~mm}$. Mode $0.24 \mathrm{~mm}$. Optically active bone fragments demonstrating a range of colours from light yellow to brown to light grey. Fragments clearly show lamella typical of fast growing mammals, e.g. pig, goat, horse.

common: Polycrystalline Quartz: el \& eq. sa-sr. $<1.20 \mathrm{~mm}$. Mode $0.48 \mathrm{~mm}$. Straight or undulose extinction. 
rare: $T F$ 's; el \& eq. sr-r. $<0.80 \mathrm{~mm}$. Mode $0.40 \mathrm{~mm}$. Brown to dark brown. High optical density. Sharp boundaries. Discordant. Optically active brown clay with sub-angular to angular quartz and some white mica. Clay pellets.

very rare: Plagioclase feldspar; eq. sr. $<0.48 \mathrm{~mm}$.

very rare: Basic igneous; eq. sr. $<0.48 \mathrm{~mm}$. Fragment consists of plagioclase feldspar and olivine crystals.

very rare: Calcite; eq. sr. $<0.32 \mathrm{~mm}$. Fine grained calcite inclusion. Could be micrite.

$\underline{\text { Fine fraction }}$

$50 \% .0 .16-0.01 \mathrm{~mm}$.

predominant: Quartz

dominant: Bone

very rare: White mica

$\underline{\text { Matrix }}$

55\%. Non-calcareous. Light brown to dark brown in PPL, light yellow brown to brown in XP (x40). Heterogeneous. Core margin colour differentiation. Optically very active.

$\underline{\text { Voids }}$

$25 \%$. Consisting of mega vughs, vesicles and mega vesicles. No alignment to margin of samples.

\section{Comments}

This sample is characterised by the use of animal bone as a tempering agent in noncalcareous clay. The laminar evident in all such inclusions suggest a fast growing mammal such as a cow, pig, sheep or horse, whilst the small size of the inclusions suggest extensive crushing to an almost powder consistency. The presence of small amounts of basic igneous and calcite, naturally occurring within the matrix, suggest an origin for the clay raw materials somewhere on the White Peak. The high optical activity and core margin colour variation suggest a relatively short, low temperature firing in an oxidising atmosphere. No sign of construction technique was evident in the section.

\section{FABRIC 14 - IRON RICH CHERT IN NON-CALCAREOUS CLAY}

Samples

SM4.

$\underline{\text { Inclusions }}$ 
$20 \%$. el \& eq. Single - open spaced. No alignment to margin of sample. Bimodal grain size distribution.

\section{$\underline{\text { Coarse fraction }}$}

$30 \%$. 3.2-0.32mm.

predominant: Iron Rich Radiolarian Chert; el \& eq. a-sr. $<2.00 \mathrm{~mm}$. Mode $1.20 \mathrm{~mm}$. Contain elongate and spherical siliceous fossils.

common: Quartz; el \& eq. sr-r. $<0.48 \mathrm{~mm}$. Mode $0.32 \mathrm{~mm}$. Undulose extinction.

rare: Chert; el \& eq. el \& eq. a-sr. $<3.2 \mathrm{~mm}$. Mode $3.20 \mathrm{~mm}$. Silica rich.

$\underline{\text { Fine fraction }}$

$10 \%$. 0.32-0.01mm.

predominant: Quartz

very rare: Phyllite

very rare: Feldspar

$\underline{\text { Matrix }}$

$35 \%$. Non-calcareous. Light brown to very dark brown in PPL, light orange brown to very dark brown in XP (x40). Heterogeneous. Core margin colour differentiation. Optical active in the margins.

\section{$\underline{\text { Voids }}$}

$25 \%$. Consisting of channels, mega-channels, and mega-vughs. No alignment to margin of samples.

\section{Comments}

This sherd from the site of Stanton Moor is characterised by the dominance of iron rich chert, a rock which occurs extensively across the White Peak, most notably in the Wye Valley. The sub-angular to rounded nature of the quartzes in the fine fraction are not indicative of a fluvial source, but could have been obtained from a nearby boulder or primary clay. The high optical activity and core margin colour variation suggest a relatively short, low temperature firing below $850^{\circ} \mathrm{c}$ in an oxidising atmosphere. No sign of construction technique was evident in the section.

\section{FABRIC 15 - IRON RICH CHERT AND WEATHERED ACID IGNEOUS} FRAGMENTS IN NON-CALCAREOUS CLAY 


\section{$\underline{\text { Samples }}$}

BH1.

\section{$\underline{\text { Inclusions }}$}

$30 \%$. el \& eq. a-sr. Single and open spaced. No alignment to margin of samples. Highly bimodal grain size distribution.

\section{Coarse Fraction}

$80 \% .3 .84-0.24 \mathrm{~mm}$

predominant: Weathered Acid Igneous. el \& eq. sa-sr. $<3.84 \mathrm{~mm}$. Mode $2.56 \mathrm{~mm}$. Similar visually to chert in its high silica content but contains phenocrysts of feldspar, some with high interference colours. One phenocrysts resembles sanadine. On account of the advanced weathering identification is difficult to securely identify the inclusions, although one relatively un-weathered fragment has been tentatively identified as rhyolite.

common: Chert; el \& eq. a-sa. $<3.2 \mathrm{~mm}$. Mode $1.44 \mathrm{~mm}$.

very few: Quartz; el \& eq. sr-r. $<0.40 \mathrm{~mm}$. Mode $0.24 \mathrm{~mm}$. Straight and undulose extinction. Can be iron rich.

rare: $T F$ 's; eq. sr-wr. $<0.40 \mathrm{~mm}$. Mode $0.16 \mathrm{~mm}$. Occur in the coarse and fine fraction. Low optical density. Sharp boundaries. Composed of pellets, possibly related to the weathering of the clay.

\section{$\underline{\text { Fine fraction }}$}

20\%. $0.24-0.01 \mathrm{~mm}$

predominant: Quartz

common: Phyllite

very rare: White Mica

\section{$\underline{\text { Matrix }}$}

45\%.Non-calcareous. Light yellow brown to very dark brown in PPL, light brown to very dark brown in XP (x40). Homogeneous. Core margin colour differentiation. Optically active in the margins.

\section{$\underline{\text { Voids }}$}

$25 \%$. Consisting of vesicles, mega vesicles, vughs and mega vughs. Slight alignment to margin of samples.

\section{Comments}


The fragment BH1 represents a sherd from an unidentified urn situated on the Gritstone Uplands, and is characterised by the addition of weathered acid igneous to non-calcareous clay, in addition to chert. The inclusions are characteristic of rocks found on the White Peak, although the former occurs only in clays of the region. The angular chert fragment may have been added intentionally or accidently, having been formed by as a by-product of knapping. The sub-angular to sub-rounded quartzes in the fine fraction do not indicate a fluvial source was utilised, but possibly a boulder or weathered clay. The poor alignment of the voids, high optical activity, and core margin colour variation suggest a relatively short, low temperature firing below $850^{\circ} \mathrm{c}$ in an oxidising atmosphere.

FABRIC 16 - QUARTZ, CHERT AND ACID IGNEOUS ROCK IN NON-CALCAREOUS CLAY

\section{$\underline{\text { Sample }}$}

SM2.

\section{$\underline{\text { Inclusions }}$}

15\%. el \& eq. sr. Open spaced. No alignment to margin of samples. Bimodal grain size distribution.

\section{Coarse Fraction}

50\%. $1.76-0.08 \mathrm{~mm}$.

dominant: Quartz; el \& eq. sr. $<0.56 \mathrm{~mm}$. Mode 0.40. Straight and undulose extinction.

common: $T F$ 's; el \& eq. sr-r. <4.0mm.Mode $1.6 \mathrm{~mm}$. Light brown to dark brown. High optical density. Discordant. Optically active brown clay. Represent weathering of clay to TF. Clay pellets, streaks, and swirls.

few: Chert; el. sr. $<0.80 \mathrm{~mm}$. Mode $0.56 \mathrm{~mm}$. Inclusions demonstrate partial radial fibrous structure, indicative of chalcedonic quartz.

rare: Weathered Acid Igneous; eq, sr, $<1.76 \mathrm{~mm}$. Mode $1.76 \mathrm{~mm}$. Inclusion is silica rich, with an appearance similar to chert, but contains phenocrysts and also epidote. Possibly an acid or intermediate rock.

rare: Weathered Basic Igneous; eq. r. <0.96. Mean 0.80mm. Appears to be dolerite.

\section{$\underline{\text { Fine Fraction }}$}

$50 \% .0 .08-0.01 \mathrm{~mm}$

predominant: Quartz. 
very rare: Phyllite

very rare: White Mica

\section{$\underline{\text { Matrix }}$}

50\%. Non-calcareous. Light brown to dark brown in PPL. Light yellow brown to dark red brown in XP (x40). Heterogeneous. Core margin colour differentiation. Optically very active.

\section{$\underline{\text { Voids }}$}

$35 \%$. Consists of macro-channels, macro-vesicles, vesicles, mega-vesicles and megavughs.

\section{$\underline{\text { Comments }}$}

This single sherd originates from the Early-Middle Bronze Age Gritstone Uplands site of Stanton Moor, and is characterised by the presence of basic igneous, chert, and acid igneous. These rocks are all found on the White Peak. Although weakly bimodal, the weathered inclusions and the clear lack of dominance of a single rock type raises the possibility that these are naturally occurring inclusions within the clay matrix. The high optical activity and colour of the clay suggest a low firing below $850^{\circ}$ in an oxidising atmosphere.

\section{FABRIC 17 - CHERT IN NON-CALCAREOUS CLAY}

\section{Sample}

SM1.

\section{Inclusions}

$5 \%$. el \& eq. sa-sr. Open spaced. No alignment to margin of samples. Bimodal grain size distribution.

\section{Coarse Fraction}

$50 \% .1 .36-0.08 \mathrm{~mm}$

predominant: Chert; el \& eq. sa-sr. Maximum diameter $<1.36 \mathrm{~mm}$.Mode $0.56 \mathrm{~mm}$.Inclusions are silica rich.

very rare: $T F$ 's; el. sr. $<1.44 \mathrm{~mm}$.Mode $1.12 \mathrm{~mm}$. Light brown to brown. High optical density. Sharp boundaries. Optically active brown clay. Represent weathering of clay to TF. Clay pellets and streaks.

\section{Fine Fraction}


predominant: Quartz.

very rare: White Mica.

\section{$\underline{\text { Matrix }}$}

75\%.Non-calcareous. Light brown to very dark brown in PPL. Light yellow brown to red brown to very dark brown in XP (x40). Heterogeneous. Core margin colour differentiation. Optically very active in oxidised areas.

$\underline{\text { Voids }}$

$20 \%$. Consists of channels, vesicles, mega-vesicles, vughs and mega-vughs.

\section{$\underline{\text { Comments }}$}

This single sherd from the Early-Middle Bronze Age consists of chert temper in relatively clean clay. The sub-angular to rounded quartzes in the fine fraction provide little information regarding provenance, but chert is widely available in the lowlands of the White Peak. The high optical activity and core margin colour variation suggest a poorly controlled firing below $850^{\circ} \mathrm{c}$ in a partially oxidising atmosphere.

FABRIC 18 - GROG, QUARTZ, AND CHLORITE Serpentinite IN NON-CALCAREOUS CLAY

\section{$\underline{\text { Samples }}$}

CP1.

$\underline{\text { Inclusions }}$

$40 \%$. el \& eq. sr-r. Single spaced. Crude alignment to margin of samples. Highly bimodal grain size distribution.

\section{Coarse Fraction}

$80 \% .1 .76-0.24 \mathrm{~mm}$

predominant: Grog; el \& eq. sa. $<1.20 \mathrm{~mm}$. Mode $0.72 \mathrm{~mm}$. Composed of straw yellow to orange brown with small amounts of fine grained quartz. Second generation grog occurs in one inclusion. Optically very active. High optical density. All samples contain shrinkage voids.

dominant: Quartz; sr-wr. $<0.56 \mathrm{~mm}$. Mode $0.48 \mathrm{~mm}$.Undulose extinction.

common: Opaques; el \& eq. sr-wr. $<0.40 \mathrm{~mm}$. Mode $0.24 \mathrm{~mm}$. Large discreet opaque inclusion. May be related to TF's. 
rare: $T F$ 's; el \& eq. sr. $<1.28 \mathrm{~mm}$. Composed of optically inactive brown clay, some containing quartz. Sharp to merging boundaries. Weathered inclusions in the fine and coarse fraction. Occurs as pellets.

rare: Argillaceous Inclusions; el \& eq. sr. $<0.40 \mathrm{~mm}$.Mode $0.24 \mathrm{~mm}$. Red brown inclusions rich in clay with occasional fine quartz inclusions. High optical density. Sharp boundaries. Discordant. Can have shrinkage voids.

very rare: Serpentinite: el. sr. $1.72 \mathrm{~mm}$. Straw yellow to red brown with opaque inclusions, after chlorite?. Shrinkage voids. Does not contain characteristic mesh like structure but tentatively identified as chlorite serpentinite.

very rare: Fibrous Inclusion; eq. r. Consists of a single inclusion which is light yellow in coloured. Consists entirely of fibrous growths which demonstrate undulose extinction and high optical activity. Demonstrates first order interference colours.

\section{$\underline{\text { Fine Fraction }}$}

20\%. $0.24-0.01 \mathrm{~mm}$.

predominant: Quartz

very rare: Phyllite

very rare: Serpentinite

very rare: White Mica

\section{Matrix}

50\%. Non-calcareous. Light yellow brown to brown to very dark brown in PPL. Light yellow brown to very dark brown in XP. Heterogeneous. Core margin colour variation. Optically active. Contains relic coil.

$\underline{\text { Voids }}$

10\%. Planar voids, channels, vesicles and mega vesicles.

\section{$\underline{\text { Comments }}$}

This single sherd originates from the Early Bronze Age barrow of Carsington Pasture on the southern limits of the White Peak. The characteristic features are a densely packed matrix dominated by grog and quartz, with a variety of other inclusions in the coarse and fine fractions, notably chlorite serpentinite. The sub-rounded to rounded quartz inclusions in the fine fraction possibly indicate a fluvial source, whilst the serpentinite in the coarse fraction is not known to occur in the area. The basic igneous rocks of the White Peak however, are the closest in character and may possibly have been altered to serpentinite in places. The small nature of the voids suggests relatively well processed clay, whilst the high optical activity and core margin colour variation indicating a poorly controlled firing below $850^{\circ} \mathrm{C}$. In comparison to Fabric 5, which 
consists of non-related sherds, this particular example was described as a loner on account of the matrix being so thoroughly different in character to its counterparts.

\section{APPENDIX 3 THIN SECTION CHARACTERISATION OF PEAK DISTRICT NATIONAL PARK GEOLOGICAL SAMPLES AND COMPARISON WITH ARCHAEOLOGICAL CERAMICS}

\section{Clay Samples}

\section{Raw Material Site 1 Sample 2 - Cave Dale}

Clay sample taken from weathered columnar basalt. Sample was dried and crushed with a pestle and mortar, removing larger fragments to improve plasticity of the clay. Contains sub-rounded to well rounded basic igneous inclusions which dominate the course and fine fractions, and are subject to varying degrees of weathering. The geological memoirs describe the parent rock as 'Columnar Basalt' but the grain size is more akin to dolerite. Inclusions which have undergone little weathering, for instance feldspars, olivines and pyroxenes, can be clearly seen, with little flow alignment. Smaller inclusions of basic igneous are heavily weathered, with a red colour akin to serpentinite. Sub-angular to sub-rounded mono-crystalline quartz with dark sub-rounded argillaceous inclusions (which may originate from the weathering of the basic igneous) are evident throughout the section. Rarer sub-angular to well rounded examples are evident in the course fraction. A few inclusions of sub-rounded to well-rounded cherts are present in the coarse fraction, with dark sub-rounded argillaceous inclusions which may originate from the weathering of the basic igneous evident throughout the section.

\section{Raw Material Site 1 Sample 3 - Cave Dale}

Clay sample taken from weathered columnar basalt and prepared as S1S2. Section is very similar to Sample 2 with sub-rounded to well rounded basic igneous inclusions which dominate the course and fine fractions, subject to varying degrees of weathering with only limited flow visible in the feldspars. The size distribution and weathering of these clasts is again comparable to the first sample, the only notable difference being the precipitation of a chert like substance partially replacing a fragment of basic igneous. Again sub-angular to sub-rounded Mono-crystalline quartz and feldspars are common in the fine fraction, in addition to a small amount of muscovite mica. Mono-crystalline quartzes in the coarse fraction are generally sub-rounded to well-rounded. Dark sub-rounded argillaceous inclusions are common and may originate from the weathering of the basic igneous evident throughout the section.

\section{Raw Material Site 1 Sample 4 - Cave Dale}

Clay sample taken from weathered columnar basalt and prepared as S1S2. Section is similar to Sample 2 with sub-rounded to well rounded basic igneous inclusions which dominate the course and fine fractions, subject to varying degrees of weathering. The size of the basic inclusions makes characterisation difficult but some of the inclusions appear to have a sub-ophitic texture, with size distribution and weathering of these clasts again comparable to the first sample. Some of these inclusions show limited flow in the feldspars. Sub-angular to sub-rounded mono-crystalline quartz is common in the 
fine fraction, with a few feldspars. Where the basic igneous inclusions have not been weathered, both olivine rich and pyroxene rich examples are evident. Dark sub-rounded argillaceous inclusions which may originate from the weathering of the basic igneous are evident throughout the section.

The three clay samples taken from Cave Dale therefore form a homogeneous group, formed by in-situ weathering of the parent columnar basalt to form dolerite rich clay. The variation between the three samples is only minor but one characteristic of note is the variability in the texture of the basic igneous inclusions, which vary in the degree of weathering and the ratio of olivine to pyroxene. Although some processing with a sieve was required the resulting clay was of a high enough standard to enable the production of pottery and would have therefore been a reasonable choice in late prehistory if the source was known at the time.

Comparison with ceramics has produced some similarities with several sections from Gardom's Edge and Mam Tor. MT19, MT21, MT22, MT48, G40, G41, G52, and G61 contain weathered and reddened basic igneous with smaller inclusions distributed throughout the clay, with similar grain size between the clay samples and inclusions in the ceramics. MT 19, MT 22, G41, G52 and G61 also contain chert. The match is not exact as the raw material samples from Cave Dale clays contain a high quantity of fine quartz and feldspar; whilst the ceramics contain a far fewer number of these. MT48 also contains shale which is not found within the Cave Dale samples. The distribution and abundance of fine, rounded and mostly weathered basic igneous (often to a red colour) is not paralleled within the ceramics, suggesting that the basic igneous was from an extremely weathered source and not from weathered basic igneous clay.

The weathered appearance of the basic igneous rocks in the Cave Dale examples are also similar to the basic igneous inclusions in HR7 at Harborough Rocks and SM9 at Stanton Moor. The clay matrices however, are not comparable, and it is therefore unlikely that the clay for these samples was sourced from here.

\section{Raw Material Site 3 Sample 2 - Mam Tor}

Clay sample taken from fluvial channel on south-west side of Mam Tor, immediately above the broken road. A high level of plasticity was demonstrated with only a small amount of processing required. All processing was done by hand, removing any larger rock inclusions. The clay is muddy brown in colour, dominated by sub-angular to subrounded mono-crystalline and poly-crystalline quartz in the coarse fraction, some demonstrating undulose extinction. Dark brown sub-rounded to well rounded argillaceous inclusions are spread throughout the clay, some of which may be shales. One such large inclusion of this type contains mono-crystalline quartz and may represent a mudstone. The fine fraction is dominated by sub-angular to sub-rounded mono-crystalline quartz with some feldspar.

It is likely that this clay is a quaternary deposit formed by the weathering of the parent rock through fluvial action. The plasticity of the clay would render this source suitable for ceramic manufacture with little preparation required.

\section{Raw Material Site 3 Sample 4 - Mam Tor}


Clay sample taken from fluvial channel on north side of Mam Tor, demonstrating a high level of plasticity, with only a small amount of processing required. Any large inclusions of rock were removed and the clay was processed by hand. Sub-angular to rounded mono-crystalline and poly-crystalline quartz are found throughout the clay. Large inclusions of coarse sub-rounded sandstone and siltstone dominate the matrix. Clay contains small amounts of rounded chert and large sub-rounded and also elongate argillaceous inclusions, some identified as shale.

It is likely that this clay is a quaternary deposit formed by the weathering of the parent rock through fluvial action. The plasticity of the clay would render this source suitable for ceramic manufacture with little preparation required. Comparison with ceramics produced no close matches but some general ones.

Sample is very similar to MT27 and MT28, both containing sub-angular to sub-rounded mono-crystalline quartz sandstone with some muscovite mica, coarse and fine grained sandstones and argillaceous minerals, with more of the latter being found in MT27. MT29 shows similarities in the size and shape of the quartz inclusions and the composition and presence of large inclusions of coarse sandstone. Shale inclusions are common in section which are not paralleled in this clay sample, but are found in greater quantities in S3S6, being very similar to those found in the ceramic. MT32 shows similarities with this sample in the composition of the coarse sandstone and general shape, distribution and density of the quartzes.

\section{Raw Material Site 3 Sample 5 - Mam Tor}

Clay sample taken from fluvial channel on north side of Mam Tor, demonstrating a high level of plasticity with only a small amount of processing was required. Any large inclusions of rock were removed and the clay was processed by hand. Clay is light brown yellow in colour with darker brown striations, dominated by sub-angular to rounded mono-crystalline and poly-crystalline quartz in the coarse fraction and fine fractions. Some rounded brown argillaceous inclusions are found throughout the coarse fraction, as is a small fragment of sub-rounded chert.

It is likely that this clay is a quaternary deposit formed by the weathering of the parent rock through fluvial action. The plasticity of the clay would render this source suitable for ceramic manufacture with little preparation required. Comparison with ceramics produced no matches.

\section{Raw Material Site 3 Sample 6 - Mam Tor}

Clay sample taken from fluvial channel on north side of Mam Tor, demonstrating a high level of plasticity with only a small amount of processing required. Any large inclusions of rock were removed and the clay was processed by hand. Being a light brown mottled colour, the matrix is dominated by sub-angular to sub-rounded monocrystalline and poly-crystalline quartz in the coarse and fine fractions. Brown and light brown sub-rounded argillaceous inclusions (possibly shale) are found throughout the matrix. Some inclusions of sandstone (quartz arenite) are also present. It is likely that this clay is a quaternary deposit formed by the weathering of the parent rock through fluvial action. The plasticity of the clay would render this source suitable for ceramic manufacture with little preparation required. 
Comparison has shown MT29 has close similarities to S3S6 in the distribution and grain size of the MCQ and PCQ in the coarse and fine fractions. The main difference is in the shape of the inclusions; although both are sub-angular to sub-rounded, there is a greater tendency towards rounded inclusions in the clay sample.

\section{Raw Material Site 3 Sample 7 - Mam Tor}

Clay sample taken from fluvial channel on north side of Mam Tor, demonstrating a high level of plasticity with only a small amount of processing required. Any large inclusions of rock were removed and the clay was processed by hand. Clay is a light brown mottled colour with paler patches, dominated by sub-angular to rounded monocrystalline and poly-crystalline quartz in the coarse and fine fractions. Rounded sandstone fragment, and sub-rounded to rounded argillaceous inclusions, some of which have been identified as shale, are found throughout the matrix. Feldspars and muscovite mica are found in small amounts in the fine fraction. It is likely that this clay is a quaternary deposit formed by the weathering of the parent rock through fluvial action. The plasticity of the clay would render this source suitable for ceramic manufacture with little preparation required. Comparison has shown similarities with MT18 in the size, distribution and shape of MCQ and PCQ, although MT18 does contain chert inclusions which are not present in the sample.

\section{Raw Material Site 3 Sample 13 - Mam Tor}

Clay sample taken from fluvial channel on north side of Mam Tor, demonstrating a high level of plasticity with only a small amount of processing required. Any large inclusions of rock were removed and the clay was processed by hand. Clay is midbrown in colour, dominated by sub-angular to sub-round mono-crystalline and polycrystalline quartz in the coarse and fine fractions. Dark brown rounded argillaceous inclusions are found throughout the clay, with one large, iron rich inclusion also visible. It is likely that this clay is a quaternary deposit formed by the weathering of the parent rock through fluvial action. The plasticity of the clay would render this source suitable for ceramic manufacture with little preparation required.

Comparison with groupings showed a close match with MT37, with a similar size and distribution of MCQ and PCQ. MT37 however, contains small amounts of dark chert. In spite of this the clay matrices look very similar. Sample is similar in the size, distribution and sorting of the quartzes to MT18 with little other inclusions present in the matrix. MT7 shows similarities in the shape and distribution of quartzes in the fine fraction, but with less larger quartz in the coarse fraction. Both sections are relatively devoid of other inclusions.

\section{Raw Material Site 3 Sample 14 - Mam Tor}

Shale sample taken from Mam Tor beds on exposed face directly opposite the northwest portion of Mam Tor. Sample was dried and crushed before being sieved to remove larger fragments. Clay is brown in colour, dominated by large rounded inclusions of dark brown, medium brown and pale straw coloured shale. A small amount of subrounded mono-crystalline quartzes occur throughout the fine fraction. The Mam Tor beds which provided the shale for this sample form part of the Upper Carboniferous 
deposits which form the Millstone Grit Series. Once processed, the sample forms highly plastic clay which would be ideal for potting. Comparison of the sample with ceramics produced comparisons with the shale rich clays of MT25, MT30, and MT48, indicating this source may have been utilised.

Clay samples from Mam Tor all contain similar characteristics, with mono-crystalline quartz and some poly-crystalline quartz dominating the ground mass, with occasional but rare inclusions of feldspar, muscovite mica and chert. Other inclusions such as shale, coarse sandstone and siltstone also occur in some examples. Comparisons with ceramics have produced close matches, mainly in the size, distribution and shape of the quartzes and are limited to pottery from the hill-fort of Mam Tor, suggesting a possible a local origin for these ceramics. There are subtle differences which suggest that the source may be near but in a different locality to the hill-fort, such as the presence of iron rich chert which is not found in any of the clay samples. The presence of large inclusions of siltstone in samples such as $\mathrm{S} 3 \mathrm{~S} 4$ are not paralleled in any of the ceramics, but may have been removed during clay processing.

\section{Raw Material Site 9 Sample 3 - Wye Valley below Fin Cop}

Sample was taken by gauge core at the edge of the River Wye in the valley below Fin Cop hill-fort. Sample was dried and crushed with a pestle and mortar, removing larger fragments to improve plasticity of the clay, and then vacuum impregnated. Clay is a mottled pale straw yellow to light brown colour, dominated by sub-angular to subrounded mono-crystalline quartz in the coarse and fine fractions with some feldspars, argillaceous inclusions, and a few rounded amorphous inclusions with bright interference colours, and a single biotite mica. Although the clay was of very poor quality, close matches were found with all the samples from Fabric 2, which were limited to the hillfort of Fin Cop.

\section{Raw Material Site 15 Sample 1 - Gardom's Edge}

Sample was taken by core from a clay band which crosses the site, not recorded on the geological map. Sample was processed by hand with any large inclusions/organics removed to preserve the colour banding evident in the sample. Clay is a mix of straw yellow and muddy colours containing sub-rounded to rounded mono-crystalline and poly-crystalline quartzes in the coarse fraction. Large sub-rounded feldspars also occur, one of which demonstrates cross-hatched twinning. A single sub-rounded chert fragment also occurs in the matrix. Dark argillaceous inclusions occur, some containing small amounts of mono-crystalline quartz which may represent mudstones. The fine fraction contains sub-angular to sub-rounded mono-crystalline quartzes.

\section{Raw Material Site 15 Sample 2 (lower) - Gardom's Edge}

Sample was taken by core from clay band which crosses the site, not recorded on the geological map. Sample was processed by hand with any large inclusions/organics removed to preserve the colour banding evident in the sample. This sample forms one of two taken from the same coring, representing the lower and more pure section. Clay is a mix of straw yellow, muddy brown and isolated red colours, forming clear bands which contain large sub-rounded to rounded mono-crystalline and poly-crystalline quartzes in the coarse and fine fractions. Dark sub-rounded and rounded argillaceous 
inclusions appear to represent shale and mudstone. Two large sub-rounded inclusions may represent altered feldspars.

\section{Raw Material Site 15 Sample 2 (upper) - Gardom's Edge}

Sample was taken by core from clay band which crosses the site, not recorded on the geological map. Sample was processed by hand with any large inclusions/organics removed to preserve the colour banding evident in the sample. This sample forms one of two taken from the same coring, representing the upper portion which showed a small amount of mixing with the sub-soil. The clay contained some dark brown banding but consisted mostly of a straw yellow colour, dominated by sub-rounded to rounded monocrystalline quartz and sub-angular to sub-rounded mono-crystalline quartz in the fine fraction. Rounded to well-rounded argillaceous inclusions are found throughout the matrix, being dark brown to red in colour, some of which probably represent mudstones.

\section{Raw Material Site 15 Sample 3 - Gardom's Edge}

Sample was taken by core from clay band which crosses the site, not recorded on the geological map. Sample was processed by hand with any large inclusions/organics removed to preserve the colour banding evident in the sample. Clay is dark to muddy brown and straw yellow in colour, forming clear bands. Large sub-rounded to rounded mono-crystalline and polycrystalline quartzes are found within the coarse fraction. Subrounded to rounded mono-crystalline quartz is found infrequently in the fine fraction. The clay matrix from this sample contains generally fewer naturally occurring inclusions than other samples taken from across the site.

\section{Raw Material Site 15 Sample 4 - Gardom's Edge}

Sample was taken by core from clay band which crosses the site, not recorded on the geological map. Sample was processed by hand with any large inclusions/organics removed to preserve the colour banding evident in the sample. Clay varies from muddy brown to light straw yellow, arranged in clear bands. Large sub-rounded mono-crystalline and polycrystalline quartzes are spread throughout the clay, with sub-rounded to rounded quartzes found in the fine fraction. The clay is on the whole, very similar to Sample 3 from this site, being relatively devoid of inclusions.

\section{Raw Material Site 15 Sample 5 - Gardom's Edge}

Sample was taken by core from clay band which crosses the site, not recorded on the geological map. Sample was processed by hand with any large inclusions/organics removed to preserve the colour banding evident in the sample. Clay varies from muddy brown to light straw yellow, arranged in clear bands. Large sub-angular to sub-rounded mono-crystalline and polycrystalline quartzes are spread throughout the coarse and fine fractions. The clay is on the whole, very similar to Sample 3 from this site, being relatively devoid of inclusions.

\section{Raw Material Site 15 Sample 7 - Gardom's Edge}


Sample was taken by core from clay band which crosses the site, not recorded on the geological map. Sample was processed by hand with any large inclusions/organics removed to preserve the colour banding evident in the sample. Large sub-angular to subrounded mono-crystalline and polycrystalline quartzes are spread throughout the clay in the course and fine fractions, with the latter containing more inclusions than in samples 3 and 4 from this site. Sample contains a possible inclusion of altered acid igneous rock.

\section{Discussion of samples from Gardom's Edge}

The clay samples from Gardom's Edge demonstrate a high level of uniformity, consisting of a mixture of light straw yellow and brown clay bands. It is likely that the Clay sample formed in situ from the parent rock, namely the Millstone Grit. The natural plasticity of the clay makes this location an excellent choice for raw material procurement. Although the amounts of Mono-crystalline and poly-crystalline quartz did vary between some sherds, the similarity of the samples make it possible to deal with them as more or less one group, comparing the samples together with ceramics that resemble them. It is of note that shale was observed in several examples, as well as feldspars and chert in S15S1.

The characteristic of brown and straw yellow clay striations is seen in G7, G8, G11, G16, G23, G25, G30, G31 and G32. Argillaceous inclusions mostly identified as shale have been recorded in Sections G1, G3, G4, G5, G6, G7, G8, G9, G10, G11, G12, G13, G14, G15, G16, G19, G20, G21, G22, G23, G25, G26, G27, G28, G29, G30, G31, G32, G33, G35, G36, G37, G40, G63, G64, G69, G91, whilst sections often contain monocrystalline and poly-crystalline quartz with little other inclusions.

G20, G66 and G42 have a clean clay matrix without many inclusions in fine fraction, similar to S15S5, without the larger MCQ and PCQ fragments. G80 also has a clean fine fraction similar to S15S5 but containing sub-angular chert. G95 contains two inclusions of fine grained acid igneous rock, in common with Clay Sample 17.

The size and shape of the mono-crystalline quartz in the above examples is complementary to those found within the Gardom's Edge clay samples. However, the quantity in the samples varies, with S15S1, S15S2U, S15S2L, and S15S7 all containing a dense concentration of small mono-crystalline quartz in the fine fraction, whilst in comparison S15S3, S15S4, and S15S5 containing few monocrystalline quartz in the fine fraction. Ceramics with comparable densities are limited to G9. All sherds have monocrystalline quartz distributed throughout the clay to varying extents, although few demonstrate an exact match in terms of distribution and quantity. Chert is found in several of the samples, namely G2, G14, G52, G66, G72, and G84 with all but G14 containing dark chert with a high iron content, which is not seen in the clay samples from Gardom's Edge.

In conclusion, there is a not a great deal of difference between the vast majority of the clays from ceramics at Gardom's Edge (with argillaceous inclusions occurring in a large number of pots but completely absent from others) a trend born out in the clay samples. Whilst the presence of two different coloured clays might indicate nine of the sections mentioned in text were constructed with clays on site, this does not preclude 
the possibility that the processing of the clays could remove such colour differences or that other local clays may be comparable.

\section{Raw Material Site 16 Sample 1 - Thirteen Bends}

Fluvial sample was taken from exposed bank of stream adjacent to the road called 'Thirteen Bends', flowing into the River Derwent, above the village of Baslow. Clay had a high level of plasticity therefore processing was conducting by hand, removing any larger inclusions. Banding and colour changes from brown to straw yellow are evident; containing rounded argillaceous inclusions throughout the matrix. Sub-angular to sub-rounded mono-crystalline and poly-crystalline quartzes dominate the coarse fraction, with some chert inclusions also visible. The fine fraction contains subrounded-rounded inclusions of mono-crystalline quartz. It is likely that this clay was formed by the weathering of underlying rocks through fluvial action. The plasticity of the clay would render this source suitable for ceramic manufacture with little preparation required. Comparison of the sample with the ceramic thin sections produced no matches.

\section{Raw Material Site 16 Sample 2 - Thirteen Bends}

Fluvial sample was taken from exposed bank of stream adjacent to the road called 'Thirteen Bends', flowing into the River Derwent, above the village of Baslow. Clay had a high level of plasticity therefore processing was conducting by hand, removing any larger inclusions. Clay shows banding and colour changes from muddy brown to straw yellow, containing rounded argillaceous inclusions throughout the matrix. Subangular to sub-rounded mono-crystalline and poly-crystalline quartzes dominate the coarse fraction, with sub-angular to sub-rounded mono-crystalline quartz in the fine fraction. Sub-angular to sub-rounded chert is common, with feldspars, muscovite mica and possible sub-rounded argillaceous inclusions also distributed throughout the matrix. It is likely that this clay was formed by the weathering of underlying rocks through fluvial action. The plasticity of the clay would render this source suitable for ceramic manufacture with little preparation required. Comparison with ceramics produced no matches.

\section{Raw Material Site 17 Sample 1 - Baslow}

Boulder clay sample taken from building site above village of Baslow. Clay had a high level of plasticity therefore processing was conducting by hand, removing any larger inclusions. Generally straw yellow to muddy brown in colour, sub-angular to subrounded mono-crystalline and poly-crystalline quartz dominate the coarse fraction, with sub-angular to sub-rounded mono-crystalline quartz in the fine fraction. Large, sub-rounded to rounded argillaceous inclusions of shale and mudstone are found throughout the matrix, with a sub-rounded inclusion of coarse sandstone (quartz arenite) also occurring. Comparison with ceramics produced no matches.

\section{Raw Material Site 26 Sample 1 - Buxton}

Boulder clay sample taken from building site on the outskirts of Buxton. Clay had a high level of plasticity therefore processing was conducting by hand, removing any larger inclusions. Clay is dark brown to brown, containing lighter brown striations. 
Rounded iron rich inclusions are common with sub-rounded to rounded chert occurring frequently. Some small dark rounded inclusions, possibly argillaceous occur, with subangular to sub-rounded mono-crystalline quartz in the fine fraction. Comparison with ceramics produced no matches.

\section{Raw Material Site 29 Sample 3 - Ible quarry}

Clay sample was taken from weathered dolerite exposure left after the abandonment of the quarry. Sample was dried, crushed with a pestle and mortar, removing larger fragments to improve plasticity of the clay. Clay is dominated in the coarse and fine fractions by weathered sub-rounded to well-rounded inclusions of basic igneous. Many inclusions are red in colour from weathering and appear almost serpentenised. Little flow is visible in less weathered examples but some have a sub-ophitic texture. Rounded to well rounded dark argillaceous inclusions are common throughout the clay and may represent weathered basic igneous. Sub-rounded to rounded mono-crystalline quartz are common throughout the coarse and fine clay fine fractions, as are feldspars.

\section{Raw Material Site 29 Sample 4 - Ible quarry}

Clay sample was taken from weathered dolerite exposure left after the abandonment of the quarry. Sample was dried and crushed with a pestle and mortar, removing larger fragments to improve plasticity of the clay. The matrix is dominated in the coarse and fine fractions by weathered sub-rounded to well-rounded inclusions of basic igneous, many being red in colour from weathering, appearing almost serpentenised. Little flow is visible in less weathered examples but some examples have a sub-ophitic texture. Rounded to well rounded dark argillaceous inclusions are common throughout the clay and may represent weathered basic igneous. Small amounts of rounded iron rich chert are also found in the clay, as is an inclusion of poly-crystalline quartz demonstrating undulose extinction. Sub-angular to sub-rounded mono-crystalline quartz is common in the fine fraction. Comparison of both Ible samples with ceramics produced no comparisons but the clay sample does contain similarities to the basic igneous clay from Cave Dale (Site 1), with the exception that there is less fine grained quartz and feldspar.

\section{Raw Material Site 31 Sample 1 - Chapel Milton}

Boulder clay sample was taken by core from a field in the village of Chapel Milton, near Chapel-en-le-Frith. Sample was dried and crushed with a pestle and mortar, removing larger fragments to improve plasticity of the clay. Matrix is light brown in colour and dominated by sub-angular to rounded mono-crystalline quartz in the coarse and fine fractions. Sub-rounded to rounded dark brown argillaceous inclusions are spread throughout the matrix.

\section{Raw Material Site 31 Sample 2 - Chapel Milton}

Boulder clay sample was taken by core from a field in the village of Chapel Milton, near Chapel-en-le-Frith. Sample was dried and crushed with a pestle and mortar, removing larger fragments to improve plasticity of the clay. Clay is a pale straw yellow colour with some muddy brown patches. Sub-rounded to rounded mono-crystalline and poly-crystalline quartz occur throughout the coarse fraction with sub-rounded to 
rounded mono-crystalline quartz in the fine fraction, all exhibiting undulose extinction. Some feldspar also occurs throughout the clay.

\section{Raw Material Site 31 Sample 3 - Chapel Milton}

Boulder clay sample was taken by core from a field in the village of Chapel Milton, near Chapel-en-le-Frith. Sample was dried, crushed with a pestle and mortar, removing larger fragments to improve plasticity of the clay. Clay is a pale straw yellow colour with some muddy brown patches. Sub-rounded to rounded mono-crystalline and polycrystalline quartz occur throughout the coarse fraction with sub-rounded to rounded mono-crystalline quartz in the fine fraction. Some feldspars also occur throughout the clay. Sub-rounded to rounded dark brown argillaceous inclusions are spread throughout the matrix.

\section{Hard Rock Samples}

\section{Raw Material Site 1 Sample 1 - Cave Dale - Basalt}

Rock sample taken from basaltic lava flow at the site of Cave Dale, behind Pevril Castle in Castleton. Heavily weathered subhedral phenocrysts have been extensively replaced by chlorite, with secondary calcite throughout the sample. Lath shaped, twinned plagioclase feldspars show no orientation. Percentage of the constituent minerals cannot be established due to alteration.

\section{Raw Material Site 1 Sample 3 - Cave Dale - Basalt}

Rock Sample of basaltic lava taken from same site as Sample 1, approximately 5 metres to the east; almost identical to Sample 1 with the exception that the phenocrysts are subhedral to anhedral, with a small amount of silicate precipitate in addition to chlorite and secondary calcite.

\section{Raw Material Site 2 Sample 1 - Speedwell Vent - Tuff or agglomerate in volcanic vent}

Rock sample taken from volcanic vent behind Speedwell Cavern and mounted in Epoxy resin. Severe weathering has rendered the original minerals unrecognisable, with the sample being a mottled dark brown to muddy brown colour, with extensive replacement by the precipitation of a silicate mineral.

\section{Raw Material Site 2 Sample 2 - Speedwell Vent - Tuff or agglomerate in volcanic vent}

Sample taken approximately 1 meter to the west of Sample 3, mounted in Epoxy, resin, and is identical to Sample 4.

\section{Raw Material Site 4 Sample 1 - Tideswell}

Rock sample is dolerite consisting of lath shaped plagioclase feldspars (40\%) showing twinning and no flow, encompassed within augite crystals (40\%), demonstrating an 
ophitic texture. Anhedral crystals of olivine (20\%) are weathered to a brown colour. Section shows heavy chloritisation.

\section{Raw Material Site 4 Sample 2 - Tideswell}

Sample similar to Sample 5 except for the smaller crystal size of the augite, olivines and feldspars, in a sub-ophitic texture, with a small amount of secondary calcite.

\section{Raw Material Site 4 Sample 3 - Tideswell}

Similar to Sample 5 with some differences, namely the presence of channels filled with secondary calcite and weathering is more severe, affecting the augite as well as the olivines.

\section{Raw Material Site 4 Sample 5 - Tideswell}

Rock sample is an olivine dolerite with phenocrysts of weathered olivine, surrounded by smaller pyroxene crystals with simple twinned lath shaped plagioclase feldspars (50\%) with flow visible in some areas of the section. Some chloritisation of sample. Difficult to estimate accurately percentage of olivine to augite in the groundmass.

\section{Raw Material Site 4 Sample 6 - Tideswell - Dolerite/basalt}

Euhedral to anhedral phenocrysts of olivine are weathered with section showing strong chloritisation. Plagioclase feldspars (50\%) are lath shaped and show a strong flow pattern. Difficult to estimate percentage of olivines and augite in the groundmass but sample was originally olivine basalt. Sample is probably a dolerite but could be on the boundary of basalt.

\section{Raw Material Site 5 Sample 2 - Ravenstor}

Sample is vesicular basalt. Sample is very weathered but subhedral phenocrysts of olivine and possibly augite are surrounding a fine grained groundmass with includes lath shaped plagioclase feldspars $(50 \%)$ with no flow. Difficult to estimate percentage of olivine and augite due to weathering.

\section{Raw Material Site 6 Sample 1 - Monsal Trail - Upper Millers Dale Lava}

Sample is basic igneous taken from the rock face on the Monsal trail and is severely weathered to the point where individual crystals can no longer be identified, with the exception of lath shaped plagioclase feldspars showing twinning and no flow. Sample shows an amygdaloidal texture with vesicles which are filled mainly with calcite but also a small amount of a silicate mineral. Some chloritisation also appears to have occurred. Sample was probably vesicular basalt.

\section{Raw Material Site 8 Sample 1 - Taddington Wood}

A fine grained groundmass consisting of lath shaped crystals of twinned plagioclase feldspar are surrounded by weathered phenocrysts of olivine and possibly pyroxene. 
Sample has heavy replacement by an unidentified mineral, and a small amount of silicate has precipitated into the rock. Weathering and replacement minerals make it difficult to estimate original mineral percentages and therefore identified as a basalt or dolerite. Iron rich opaque phenocrysts are also present in the rock. Cracks through the sample are filled by the precipitation of a brown argillaceous mineral.

\section{Raw Material Site 9 Sample 1 - Quarry near River Wye}

Rock sample was taken from the face of a small disused quarry working in a wood near the banks of the River Wye below Fin Cop. Sample is a vesicular olivine basalt with euhedral to subhedral olivine phenocrysts surrounded by a groundmass of the same constituents. Flow is visible in the twinned, lath shaped feldspars. Fine cracks through the rock sample contain secondary amorphous mineral. Rock sample has high iron content and is heavily chloritised, therefore difficult to estimate percentages.

\section{Raw Material Site 9 Sample 2 - Quarry near River Wye}

Sample taken within one meter of Sample 13, again being basalt with euhedral to anhedral phenocrysts of olivine, with one crystal being elongate. Twinned plagioclase feldspar laths are found throughout the micromass, with no flow visible. Secondary calcite has precipitated into the groundmass. Rock sample has a spherical intergrowth of an iron rich, opaque inclusion bounded by plagioclase feldspars with iron rich lamellar intergrowths on the interior. A vesicle filled with chlorite is also present. Sample has high iron content.

\section{Raw Material Site 10 Sample 1 - Calton Hill Quarry}

Sample is recorded as dolerite but has a texture consistent with olivine rich basalt. Euhedral to subhedral crystals of weathered olivine (20\%) are surround by a fine grained groundmass of lath shaped, simply twinned plagioclase feldspars (65\%). Olivines are weathered to a variety of colours, with some sections of the sample demonstrating chloritisation. Sample is particularly iron rich in the groundmass.

\section{Raw Material Site 10 Sample 2 - Calton Hill Quarry}

Similar to S10S1 but with larger crystals (still basalt).

\section{Raw Material Site 10 Sample 3 - Calton Hill Quarry}

Same as S10S1.

\section{Raw Material Site 10 Sample 4 - Calton Hill Quarry}

Similar to S10S1 but with larger feldspar which demonstrate limited flow.

\section{Raw Material Site 11 Sample 1 - Black Rock Corner}

Rock sample is olivine rich vesicular basalt with amygdaloidal features and high iron content. Subhedral phenocrysts of olivine which have been heavily chloritised are surrounded by a fine grained groundmass of lath shaped twinned plagioclase feldspar 
(50\%) showing strong flow. Vesicles are filled with secondary calcite. Chloritisation makes it difficult to estimate other percentages but sample is olivine rich.

\section{Raw Material Site 11 Sample 2 - Black Rock Corner}

Sample is iron rich vesicular olivine basalt, with euhedral to anhedral olivine phenocrysts surrounded by a fine grained groundmass of olivine; lath shaped twinned plagioclase feldspars showing clear flow patterns and a small amount of augite. Groundmass is iron rich with secondary chlorite found throughout sample and one vesicle.

\section{Raw Material Site 11 Sample 3 - Black Rock Corner}

Sample very similar to Sample 17, including iron rich inclusions.

\section{Raw Material Site 11 Sample 4 - Black Rock Corner}

Olivine rich basalt with subhedral phenocrysts of olivine surrounded by a groundmass of lath shaped, twinned plagioclase feldspars (40\%) with no flow and weathered minerals making it difficult to estimate percentages. Groundmass is coarser than with other samples from this site, also containing opaque iron rich inclusions. Groundmass contains larger crystals than many other samples from this site.

\section{Raw Material Site 11 Sample 5 - Black Rock Corner}

Rock sample has a grain size consistent with dolerite. Weathered anhedral olivines (20\%) are surrounded by augite $(40 \%)$ with lath shaped, twinned plagioclase feldspars (40\%) showing some flow. Sample is iron rich.

\section{Raw Material Site 11 Sample 6 - Black Rock Corner}

Rock sample of dolerite containing phenocrysts of weathered subhedral olivine (10\%) surrounded by smaller crystals of augite $(40 \%)$ and lath shaped, twinned and zoned plagioclase feldspar (40\%).

\section{Raw Material Site 11 Sample 7 - Black Rock Corner}

Similar to Sample 22 but with slightly smaller grain size

\section{Raw Material Site 11 Sample 8 - Black Rock Corner}

Very similar to Sample 23

\section{Raw Material Site 11 Sample 9 - Black Rock Corner}

Very similar Sample 16

\section{Raw Material Site 12 Sample 1 - Bobbin Mill}

Rock sample taken from quarry face behind Bobbin Mill, in the Wye Valley, showing amygdaloidal features with phenocrysts of olivine replaced by chlorite and secondary 
calcite. Relatively finer groundmass of twinned plagioclase feldspar showing some flow surrounds phenocrysts of plagioclase feldspar up to $4 \mathrm{~mm}$ in length.

\section{Raw Material Site 13 Sample 1 - Taddington}

Rock sample taken from small exposure next to roadside above the village of Taddington. Sample is vesicular olivine basalt with weathered euhedral to subhedral phenocrysts of olivine surrounded by a fine grained groundmass of twinned, lath shaped plagioclase feldspars. Vesicles have an amygdaloidal texture, filled with secondary calcite and chlorite.

\section{Raw Material Site 14 Sample 1 - Brightgate Farm above Matlock}

Rock sample was taken from a trackway exposure and has undergone sever weathering of all constituent minerals with anhedral phenocrysts of olivine replaced by chlorite and silicate. No flow is visible in the lath shaped, twinned plagioclase feldspars. Sample was probably olivine basalt.

\section{Raw Material Site 14 Sample 2 - Brightgate Farm above Matlock}

Rock sample was taken from the same trackway exposure as few metres from Sample 27 , being vesicular and severely weathered, showing replacement of the vesicles by amorphous material. Twinned, lath shaped plagioclase feldspars with a porphyritic texture show no flow although size of visible crystals suggests this is a dolerite.

\section{Raw Material Site 14 Sample 3 - Brightgate Farm above Matlock}

Rock sample was taken from an exposure of lava several hundred metres to the north of Samples 28 and 29. This sample appears to be extremely weathered iron rich brachiated lava, containing subhedral olivine extensively replaced by a silicate mineral. Where visible lath shaped and twinned plagioclase feldspar shows no flow alignment. Rock sample appears to have amygdaloidal features with voids filled with an iron rich silicate mineral.

\section{Raw Material Site 19 Sample 1 - Potluck Peak Forest Dolerite Sill - Dolerite}

Rock sample of dolerite was taken from the waste of a recent quarry working in the main complex of Potluck Farm in the Peak Forest. Containing partially chloritised olivines (20\%) surrounded by augite crystals (30\%) partially enclosing lath shaped, twinned plagioclase feldspars $(50 \%)$ in a sub-ophitic texture. This sample represents a relatively coarse grained dolerite.

\section{Raw Material Site 20 Sample 1 - Old Dam Peak Forest - Dolerite}

Sample was taken from quarry waste from a dolerite mine in the village of Old Dam, Peak Forest. Sample consists of large weathered subhedral olivines (30\%), surrounded by augite $(30 \%)$, encompassing twinned, lath shaped crystals of plagioclase feldspar $(30 \%)$ in an ophitic texture. Iron minerals make up the remaining $10 \%$. This sample represents a relatively coarse grained dolerite. 
Raw Material Site 20 Sample 2 - Old Dam Peak Forest - Dolerite

Sample virtually identical to Sample 31.

\section{Raw Material Site 21 Sample 1 - Damside Farm Peak Forest Dolerite}

Sample is very similar to Sample 21. Main differences are that this relatively coarse grained dolerite contains iron rich striations in one of the augite crystals.

\section{Raw Material Site 21 Sample 3 - Damside Farm Peak Forest Dolerite}

Sample similar to Sample 20.

\section{Raw Material Site 22 Sample 1 - Tunstead near Buxton}

Rock sample is olivine basalt containing weathered phenocrysts (30\%) which are subhedral to anhedral in shape and represent olivine and possibly pyroxene, some of which show partial replacement by a silicate mineral. Surrounding these phenocrysts are twinned, lath shaped plagioclase feldspars $(40 \%)$ demonstrating no flow, olivine crystals $(15 \%)$ and iron rich inclusions (15\%).

\section{Raw Material Site 22 Sample 2 - Tunstead near Buxton}

Very similar to sample 22 but with some flow visible in the feldspars.

\section{Raw Material Site 23 Sample 1 - Ashbourne - Buxton Road}

Rock sample is a heavily weathered and chloritised dolerite with secondary silicate also present. All original minerals demonstrate extensive alteration in addition to the presence of amorphous iron rich areas. Where visible, feldspar relics are lathe shaped and show no visible flow pattern.

\section{Raw Material Site 23 Sample 2 - Ashbourne - Buxton Road}

Sample is highly altered with extensive replacement of origin minerals by chlorite and secondary calcite. Plagioclase feldspars are lath shaped, twinned and do not demonstrate flow.

\section{Raw Material Site 24 Sample 1 - Farmhouse, near Buxton}

Sample taken from a basic igneous boulder. Consists of severely weathered anhedral phenocrysts, some containing secondary calcite. Plagioclase feldspars are twinned, lath shaped and do not demonstrate flow. Some smaller olivine crystals survive in the groundmass. Iron rich minerals have possibly replaced feldspars. Could not estimate original percentage of minerals but probably olivine basalt.

\section{Raw Material Site 25 Sample 1 - Waterswallows Quarry}


This dolerite sample comes from waste at the site of Waterswallows quarry, and consists of lath shaped, twinned feldspars $(65 \%)$ which do not demonstrate flow, surrounded by crystals of weathered and un-weathered olivine and augite (30\%), with some iron rich minerals $(5 \%)$.

\section{Raw Material Sample 2 - Waterswallows Quarry}

This sample of olivine dolerite contains phenocrysts of weathered and chloritised euhedral to subhedral olivine (15\%) surrounded by a weathered and chloritised groundmass consisting of lath shaped and twinned plagioclase feldspar (50\%), with no flow and a few un-weathered olivine crystals.

\section{Raw Material Site 25 Sample 3 - Waterswallows Quarry}

Rock sample very similar to Sample 39.

\section{Raw Material Site 25 Sample 4 - Waterswallows Quarry}

Rock sample very similar to Sample 39.

\section{Raw Material Site 27 Sample 1 - Tissington - Fragmented Lava}

Sample is highly weathered vesicular basalt with amygdaloidal features, filled with silicate and amorphous minerals (possibly chlorite). Original minerals are weathered to such an extent that only a few lath shaped plagioclase feldspars demonstrate no orientation.

\section{Raw Material Site 27 Sample 2 - Tissington - Fragmented Lava}

Similar to Sample 43 with the exception that the feldspars are less weathered and the vesicles are not filled with any secondary material.

\section{Raw Material Site 27 Sample 3 - Tissington - Fragmented Lava}

Similar to Sample 43.

\section{Raw Material Site 28 Sample 1 - Matlock - Dolerite}

This sample of dolerite was taken from a field wall. Sample consists of weathered subhedral olivine crystals (30\%), with lath shaped and twinned sub-ophitic plagioclase feldspars (30\%) partially contained within augite crystals $(30 \%)$. Iron rich minerals $(10 \%)$ are also present.

\section{Raw Material Site 28 Sample 2 - Matlock - Dolerite}

Rock sample as the same as Sample 46.

Raw Material Site 29 Sample 2 - Ible - Dolerite 
Rock sample comes from the face of an abandoned quarry in Ible, consisting of weathered crystals of subhedral olivine (40\%) surrounded by augite crystals $(30 \%)$ partially containing twinned, lath shaped plagioclase feldspars $(25 \%)$ in a sub-ophitic texture which do not demonstrate flow, and iron rich inclusions (5\%). Chlorite fills the channels traversing the sample.

Raw Material Site 29 Sample 3 - Ible - Dolerite

Same as Sample 48

\section{Raw Material Site 30 Sample 1 - Grangemill}

This highly weathered sample of vesicular basalt demonstrates amygdaloidal features with replacement silicate minerals and secondary calcite, chlorite and amorphous minerals. Occasional altered relic feldspars can be seen but is impossible to estimate percentages of original constituent minerals.

Raw Material Site 30 Sample 1 - Grangemill

Sample is the same as Sample 50.

\section{APPENDIX 4. PETROGRAPHIC CHARACTERISATION OF POSSIBLE DAUB FRAGMENTS FROM FIN COP AND GARDOM'S EDGE}

\section{Gardom's Edge}

\section{G98}

The sample is a weathered basic igneous fragment with a medium grain size consistent with dolerite. Sample has a sub-ophitic texture with simply twinned plagioclase feldspars (40\%) encompassed within crystals of anhedral augite (60\%). Weathering has reduced many augite crystals to a dark brown colour. Plagioclase feldspars show no flow.

\section{G99}

Same as G98 but with larger feldspars.

\section{G100}

Same as G98 but more weathered.

\section{G101}

The sample is a weathered basic igneous fragment with a fine grained porphyritic texture. Large, mostly weathered anhedral to subhedral olivine phenocrysts $(20 \%)$ embedded in a fine grained groundmass of plagioclase feldspar (50\%), olivine $(25 \%)$ and augite $(5 \%)$, with no flow visible in the feldspars. Sample is consistent with olivine basalt. 


\section{G102}

Sample is very similar to G101 with the exception that the weathering of the olivines is more severe.

\section{G103}

Although classified as olivine rich basalt, the feldspars are generally larger than those found in G102. Larger anhedral to subhedral olivine crystals $(20 \%)$ are generally weathered, contained within a fine grained groundmass of twinned plagioclase feldspar (40\%) showing no flow, and olivine (40\%).

\section{G104}

Sample is composed of sub-angular to sub-rounded mono-crystalline quartz with an average grain size of $0.40 \mathrm{~mm}(98 \%)$ and sub-angular to sub-rounded poly-crystalline quartz $(2 \%)$ of the same average size. Quartzes are contained within a dark brown matrix $(15 \%)$. Quartz crystals are poorly sorted. Sample can therefore be classed as a muddy quartz arenite.

\section{G105}

Same as G98.

\section{G106}

Sample believed by excavators to be a fragment of clay daub. Consists of a mottled straw yellow to muddy brown clay containing infrequent sub-angular to sub-rounded mono-crystalline quartz in the coarse and fine fractions. Sample is very similar to clay sample S15S5, from Gardom's Edge.

\section{G107}

Fine grained basalt with porphyritic texture. Larger olivine phenocrysts (20\%) are anhedral and weathered to a brown colour, encompassed in a fine grain matrix of twinned feldspar showing no flow, olivine and small amounts of augite.

\section{G108}

Fine grained olivine basalt with porphyritic texture. Large phenocrysts of weathered subhedral to anhedral olivine (15\%) contained within a fine grained matrix of twinned plagioclase feldspar (30\%) showing no flow, olivine (40\%) and pyroxene (15\%).

\section{G109}

Fine grained vesicular basalt, severely weathered to a light brown mottled colour with no visible flow in the feldspars. Some secondary precipitation of a silicate rich mineral. Difficult to estimate percentage of constitute minerals, although feldspars account for approximately $45 \%$. 


\section{G110}

Almost identical to G109 but containing more vesicles. One vesicle demonstrates amygdaloidal features, filled with an amorphous material containing sub-angular to sub-rounded mono-crystalline quartz.

\section{G111}

Olivine basalt with large phenocrysts of weathered euhedral to anhedral olivine in a groundmass of twinned plagioclase feldspar (40\%) showing no flow, olivine and pyroxene, although weathering makes it difficult to estimate the percentages.

\section{G112}

Same as G111

\section{G113}

Weathered basalt with large weathered subhedral and anhedral phenocrysts (10\%), some identified as olivine's but others which could be either olivine or pyroxene, surrounded by a groundmass of twinned plagioclase feldspar with no flow, olivine and pyroxene. Weathering has made it difficult to estimate percentages.

\section{G114}

Vesicular basalt almost identical to G110 but with some smaller vesicles containing amygdaloidal features filled silicate rich mineral.

\section{G115}

Vesicular basalt almost identical to G110 but more vesicles are filled with amorphous material of the same type.

\section{G116}

Weathered basalt with no flow visible, similar to G112

\section{G117}

Olivine basalt containing weathered reddish brown anhedral phenocrysts $(25 \%)$ in a fine grained groundmass with no flow visible. Difficult to estimate percentage due to weathering but approximately $50 \%$ is twinned feldspar, with the majority being olivine, and some pyroxene.

\section{G118}

Vesicular basalt similar G112 but slightly finer grained.

\section{Discussion}


A comparison of the possible basic igneous temper with inclusions in the ceramics from the site produced a large number of matches. Samples G15, G94, G98, G99, G100 and G105 are all classed as dolerites with poikalitic texture consisting of plagioclase feldspar in clinopyroxene. Olivine is absent. The homogeneity in composition and grain size for these samples suggests the same origin. Similar inclusions were found in G28, G86, G77, G87, G89 and G91, where grain size and constituent minerals were identical but with far less weathering. These examples also included other basic igneous inclusions which did not match any of the rock fragments.

Olivine basalt sample G111 found parallels in G57, G60, and G66, whilst weathered basalt G116 showed was very similar to temper in G52, G78 and G80. G117 showed close parallels to inclusions in G47, G53, G58, G61, G63, and G88. Ceramic G56 contains basic igneous very similar to weathered basalt G113. In all these examples other inclusions of basic igneous occur in the ceramics which do not find parallels amongst the basic igneous rock fragments.

Comparison of the Gardom's Edge ceramics and rock fragments also showed that a significant quantity of sherds produced matches for more than one basic igneous rock sample, for instance G5 contained temper which matched G99 (dolerite) and G113 (basalt). G17 contained matches with the fine grained basalt of G111 and G98. G18 and G19 again contained similar inclusions to G99 but also weathered basalt similar to G111. G24 contained inclusions similar to the weathered olivine basalts of G111 and G112. G55 contained temper which matched G111 and G116, whilst G62 contained temper similar to G99 and G102. Finally G95 contained temper which was similar to G99 and olivine basalt G101. No comparisons in the ceramics were found in the weathered, fine grained vesicular basalts of G109, G110, G114 and G115, all of which were very similar and could have come from the same source.

Analysis of the basic igneous fragments recovered at Gardom's Edge suggests that several sources were being utilised across the landscape as there is a marked variety in the grain size, degree of weathering and percentage of constituent minerals, with both basalts and dolerites being utilised. The evidence also presents the possibility that the basic igneous was then used as temper for the pottery from Gardom's Edge, with more than one source of the raw material added to each pot. The fact that only some of these samples produced matches can be accounted for by either the rejection of certain sources during the production process or that the temper occurs in pots from the site which was not sampled for this thesis. This is supported by the fact that a large proportion of the ceramics sampled from this site contained inclusions not represented among the possible unused temper.

\section{$\underline{\text { Fin Cop }}$}

\section{FC15}

Rock sample is a dolerite consisting of twinned plagioclase feldspars (50\%) with no flow visible contained within weathered anhedral phenocrysts of pyroxene (40\%) in a poikalitic texture. Small amounts of olivine (10\%) are also visible. Secondary precipitation of a silicate mineral is seen in one of the weathered pyroxene minerals.

\section{FC16}


Rock sample is a vesicular dolerite containing twinned plagioclase feldspar with some flow visible in places, surrounded by weathered and anhedral phenocrysts of olivine and pyroxene but weathering make it difficult to estimate percentages. However sample is very similar to $\mathrm{FC} 15$.

\section{FC17}

Very similar to FC2 and FC3, possibly with remnants of vesicles but difficult to tell.

\section{FC18}

Similar to samples FC2-5 but with smaller feldspars. Sample is an olivine rich dolerite with $45 \%$ plagioclase feldspars but difficult to estimate exact percentage of olivine.

\section{FC19}

Dolerite with anhedral crystals of pyroxene (60\%) encompass twinned plagioclase feldspar (40\%) in a sub-ophitic texture with no olivine visible. Sample is very similar to Gardom's Edge samples G98-100 and G105.

\section{FC20}

Dolerite with very weathered phenocrysts of augite (55\%) surrounding twinned plagioclase feldspars $(45 \%)$ with some flow visible in a sub-ophitic texture. Sample is possibly vesicular but difficult to tell.

\section{Discussion}

Comparison of the basic igneous rock fragments found at Fin Cop with the temper in the ceramics only produced a match with FC19, with virtually identical inclusions found in ceramics FC3, FC4, FC5, FC10, and FC12. 